\title{
Translaçâo do Conhecimento na qualificação da gestão da Vigilância em Saúde: contribuição dos estudos avaliativos de pós-graduação
}

\section{I ${ }^{1}$ Luciana Caroline Albuquerque Bezerra, ${ }^{2}$ Eronildo Felisberto, \\ ${ }^{3}$ Juliana Martins Barbosa da Silva Costa, ${ }^{4}$ Zulmira Hartz I}

Resumo: Sáo muitos os desafios no sentido de minimizar as lacunas existentes entre evidências científicas e melhores resultados de saúde. A translaçáo do conhecimento (TC) é o movimento que o conhecimento faz em um contexto organizacional em prol da sua efetiva aplicação. O objetivo deste estudo foi analisar a ocorrência da TC na Secretaria Executiva de Vigilância em Saúde de Pernambuco (SEVS/PE), tomando como objeto dez pesquisas avaliativas sobre programas da Vigilância em Saúde, produzidas no Mestrado de Avaliação em Saúde do Instituto de Medicina Integral Prof. Fernando Figueira, de 2011 a 2015. Para tanto, utilizou-se um roteiro de entrevista semiestruturada, abordando sete gestores e dez técnicos da SEVS-PE. Na análise deste estudo de caso, qualitativo, foi utilizado um modelo de TC, e sobrepondo-se a ele, uma estrutura teórica de uso-influência da avaliação. Em oito pesquisas analisadas, foram categorizadas evidências em cinco fases $\mathrm{da}$ TC. Apenas a etapa de avaliação do uso do conhecimento não foi evidenciada. Diferentes tipos de uso, dimensões e níveis de influência das avaliaçôes foram relatados. Dentre as mudanças ocorridas, foram relatadas: criaçáo de novas agendas, elaboração de protocolos, mudança do processo de trabalho, instituiçáo de novos fluxos, contrataçáo de novos profissionais.

> Palavras-chave: translação do conhecimento; gestão do conhecimento; políticas de saúde; gestão da saúde; vigilância em saúde.

\author{
1 Instituto de Medicina Integral \\ Professor Fernando Figueira. Recife- \\ PE, Brasil (lua_cad@yahoo.com.br). \\ ORCID: 0000-0001-6074-6072 \\ ${ }^{2}$ Instituto de Medicina Integral \\ Professor Fernando Figueira. \\ Recife-PE, Brasil (eronildo. \\ felisberto@gmail.com). \\ ORCID: 0000-0002-2316-2251

\section{${ }^{3}$ Núcleo de Ciências da Vida, Universidade Federal de Pernambuco. Recife-PE, Brasil (julimartins.costa@gmail.com). ORCID: 0000-0002-5809-4156 \\ ${ }^{4}$ Instituto de Higiene e Medicina Tropical, Universidade Nova de Lisboa. Lisboa, Portugal (zhartz@ ihmt.unl.pt). \\ ORCID: 0000-0001-9780-9428}




\section{Introdução}

A utilização dos resultados de pesquisas e estudos avaliativos na prestação dos serviços de saúde, em especial aqueles desenvolvidos nas instâncias de gestão, enfrenta barreiras frequentemente identificadas entre os pesquisadores e os usuários do conhecimento produzido (BENNET et al., 2003; DAVIS, 2005; MELINE; PARADISO, 2003). Não obstante os esforços despendidos no sentido de minimizar as lacunas existentes entre evidências científicas, formulaçáo de políticas, implantação de programas e melhores resultados de saúde, fatores como: a falta de tempo, de acesso a recursos de informática e à literatura de pesquisa, e reduzidos níveis de aplicabilidade, habilidades e motivação, são obstáculos muito comumente citados em estudos realizados no Brasil e em outros países (BENNET et al., 2003; GRAHAM et al., 2006; GRAVEL; LÉGARÉ; GRAHAM, 2006; OELKE; LIMA; ACOSTA, 2015; WHO, 2005).

Colocar novos conhecimentos em prática é um processo complexo e apenas o fato de serem criados frequentemente não é suficiente para mudar atitudes e comportamentos dos decisores políticos. Isto depende do preparo técnico e da habilidade de quem vai usá-lo, de fatores organizacionais de suporte, do envolvimento contínuo dos potenciais usuários do conhecimento, das parcerias estabelecidas, do contexto institucional e da existência de mediadores do conhecimento (JACOBSON; BUTTERILL; GOERING, 2003; GAGLIARD et al., 2016; TRICCO et al., 2016; VINGILIS et al., 2003; WHO, 2005).

Diferentes nomenclaturas e conceitos descrevem a transformação do conhecimento em ação ou o uso do conhecimento produzido ou, ainda, o compartilhamento desse conhecimento. Ottoson, em 2009, descreveu cinco teorias do "conhecimento em ação" que possuem tipologias e raízes disciplinares e contextuais distintas, embora guardem relação entre seus conceitos, linguagem e cultura:

1. A utilizaçáo do conhecimento entendida sob diversas perspectivas a depender do campo (políticas públicas, administração, tecnologia), tipo de usuário final (pesquisador, elaborador de políticas, consumidor) ou contexto (organizaçáo, sociedade) (BLAKE; OTTOSON, 2009).

2. A difusáo do conhecimento, que tem a ver com a comunicação ao longo do tempo e por distintos canais entre os membros da sociedade (OTTOSON, 2009; ROGERS, 2003). 
3. A implementaçáo do conhecimento - estágio que se encontra entre o desenvolvimento das políticas e o seu impacto; o papel do usuário é determinante na implementação (O’TOOLE, 2000; OTTOSON, 2009).

4. A transferência do conhecimento, que relaciona o objeto, o contexto e os mecanismos de transferência, tendo a utilização do conhecimento em seu núcleo de forma unidirecional, lateral ou hierárquica (BLAKE; OTTOSON, 2009; OTTOSON, 2009).

5. A translaçáo do conhecimento (TC), que engloba os conceitos acima e surge como uma crítica à falta de interação entre o saber científico, os demais saberes e a produção de um conhecimento capaz de ser aplicado e utilizado na tomada de decisão. Aborda o movimento que o conhecimento pode fazer em um contexto organizacional em prol da sua efetiva aplicação (GRAHAM et al., 2006; CIHR, 2012; BARBOSA; PEREIRA NETO, 2017).

Estratégias de TC aproveitam o conhecimento produzido, as evidências e a liderança para informar e transformar a prática das políticas (DAVISON, 2009). São as interaçôes entre os produtores e os utilizadores do conhecimento, cuja intensidade, complexidade e grau de compromisso podem variar em função da natureza da pesquisa, resultados e das necessidades particulares de cada utilizador (CIHR, 2012).

Três fatores devem ser levados em conta na TC, ao tentar distingui-la das outras teorias. O primeiro é que a translação tem como objeto o conhecimento científico, particularmente na área da saúde, e o seu processo de transformação em resultados e ganhos para o sistema de saúde. O segundo é que seu foco é voltado à interação entre os vários atores (stakeholders e público-alvo) e à adequada aplicação em vários contextos. Por último, é o fato de ser um processo iterativo e multidirecional, podendo ocorrer em múltiplos estágios do ciclo do conhecimento (DAVISON, 2009).

Sáo vários os modelos de TC (CRAVEIRO; HARTZ, 2016; SUDSAWAD, 2007), a depender do foco que se queira dar: no ciclo de pesquisa, a partir das etapas de uma pesquisa (CIHR, 2005); na interação entre pesquisador e usuário (; JACOBSON; BUTTERILL; GOERING, 2003; LAVIS et al., 2006; PHAC, 2012); no contexto (GRAHAM; LOGAN, 2004; GRAHAM et al., 2006); no uso do conhecimento (BRETT, 1987; ESTABROOKS, 1999; HARTZ et al., 2008; MICHEL; SNEED, 1995). 
Independente do modelo adotado, alguns fatores podem influenciar a TC facilitando ou dificultando esse processo. Entre os facilitadores, pode-se citar: a produção de evidências relevantes e acionáveis; a credibilidade dos mediadores; o fácil acesso ao conhecimento e às agências de financiamento; o compromisso político; a compreensão do ambiente sociopolítico; o diálogo e integração entre usuários e pesquisadores no uso do conhecimento e nas decisóes; e as formas inovadoras de partilhar o conhecimento. Em contraposição, seriam dificultadores: a falta de um quadro comum para a TC; o processo caro e lento de produção de conhecimento; a competição distorcida e tendenciosa das fontes de conhecimento; a baixa demanda por evidência científica pelos decisores políticos; e as razóes políticas ou financeiras para não agir diante das evidências (WHO, 2006).

Logo, apesar dos 40 anos de pesquisa em políticas baseadas em evidências (OLIVER; LORENC; INNVAER, 2014), muitos são os desafios para os formuladores de políticas e pesquisadores aumentarem o uso do conhecimento produzido, ainda que se observe um foco crescente na governança de pesquisa e na prestação de contas dos benefícios do investimento feito pelos governos (CIHR, 2005).

Nessa perspectiva, Graham et al., em 2006, propuseram um modelo baseado em teorias de ação planejada, com o objetivo de auxiliar gestores a controlar variáveis que influenciam a ocorrência de mudanças desejadas. O modelo era composto de seis "fases ideais", dinâmicas e interdependentes, que levavam à aplicação do conhecimento: identificar um problema que precisa ser abordado; identificar, analisar e selecionar o conhecimento ou a pesquisa relevante para o problema; adaptar o conhecimento ou pesquisa identificados ao contexto local; avaliar barreiras ao uso do conhecimento; selecionar, adaptar e implementar intervençóes para promover o uso do conhecimento (ou seja, implementar a mudança); monitorar o uso do conhecimento; avaliar os resultados da utilização do conhecimento; sustentar o uso contínuo do conhecimento.

Entre as políticas de saúde do Estado de Pernambuco, aquelas vinculadas à Vigilância em Saúde têm recebido investimentos contínuos desde 2011, visando à qualificação e construção de capacidade de gestores e técnicos dos três níveis de atuação (central, regional e municipal). Os incentivos acontecem, seja por meio de parcerias com instituiçóes de ensino e pesquisa, seja por iniciativa dos interessados e apoio institucional para formação. Como contrapartida, espera-se que os profissionais 
desenvolvam projetos de estudo e pesquisa orientados para necessidades e problemas de saúde locais em busca de novos conhecimentos e soluções.

A necessidade de responder a perguntas relacionadas ao uso do conhecimento produzido por esses estudos, aliada à importância de se aplicarem modelos teóricos de TC no contexto brasileiro, demarca o objetivo deste estudo, que foi o de analisar a ocorrência da TC na Secretaria Executiva de Vigilância em Saúde de Pernambuco (SEVS/PE), tomando como base as pesquisas avaliativas - produtos dos cursos de pós-graduação de seus profissionais.

\section{Método}

Trata-se de estudo qualitativo do tipo estudo de caso, no qual o caso foi a Secretaria Executiva de Vigilância em Saúde de Pernambuco (SEVS/PE), no período de 2011-2015. A SEVS/PE é uma das seis Secretarias Executivas da Secretaria Estadual de Saúde de Pernambuco, Brasil, responsável pelo conhecimento e controle dos determinantes, riscos e danos à saúde da população, com a finalidade de recomendar e adotar medidas de promoção, prevenção e controle. Esta Secretaria agrega a vigilância de doenças transmissíveis, agravos não transmissíveis, promoção da saúde, saúde do trabalhador, sistemas de informação, além das vigilâncias ambiental e sanitária, e do laboratório de saúde pública. O estudo tem como base a produção do conhecimento, a partir do processo de formação (pós-graduação) promovido e fomentado pela gestáo da SEVS/PE.

As pesquisas avaliativas analisadas foram resultado de dez dissertaçôes do mestrado profissional de Avaliação em Saúde. Os pesquisadores eram gestores ou técnicos da SEVS/PE, das áreas de: Centro de Informaçōes Estratégicas da Vigilância em Saúde - CIEVS (P1); Gestão do Serviço de Verificação de Óbito - SVO (P2); Sistema de Informação sobre Mortalidade - SIM (P3); Sistema de Informação sobre Natalidade - Sinasc, em Pernambuco (P4), e em âmbito municipal (P5); Vigilância Epidemiológica, em Pernambuco (P6), e nas Gerências Regionais de Saúde Geres (P7); Emergências em Saúde Pública (P8); Vigilância das Arboviroses (P9); Vigilância dos Acidentes de Transporte Terrestre (P10).

Os dados foram coletados de maio a julho de 2017 por meio de entrevistas semiestruturadas, gravadas e, posteriormente, transcritas pelos próprios entrevistadores. Foram entrevistados 17 informantes-chave: quatro diretores (D1, D2, D3, D4) 
e três gerentes (Ger.1, Ger.2, Ger.3) das áreas cujos objetos foram alvo de estudos avaliativos; e dez profissionais - autores desses estudos avaliativos. Nos resultados, foram feitas citaçôes diretas das falas dos gestores, enquanto que o conteúdo das falas dos pesquisadores foi categorizado na matriz de análise.

O roteiro das entrevistas foi elaborado a partir do modelo de Conhecimento para a Ação (Knowledge to action - KTA) desenhado por Graham et al. (2006), contemplando seis fases ideais que o conhecimento percorre, transformandose em ação. Para cada fase do KTA, foram elaboradas questôes, complementadas pelo modelo global de oportunidades de TC durante a investigação, do Canadian Institute of Health Research - CIHR (2005); pela Ferramenta para Elaboração de um Plano de Translação do Conhecimento, da Public Health Agency of Canada, de 2012; e pelo Guia de planejamento da aplicação dos conhecimentos nos IPSC: abordagens integradas e de fim de subvenção, dos institutos de pesquisa em saúde do Canada (IPSC), de 2012 (Tabela 1). 


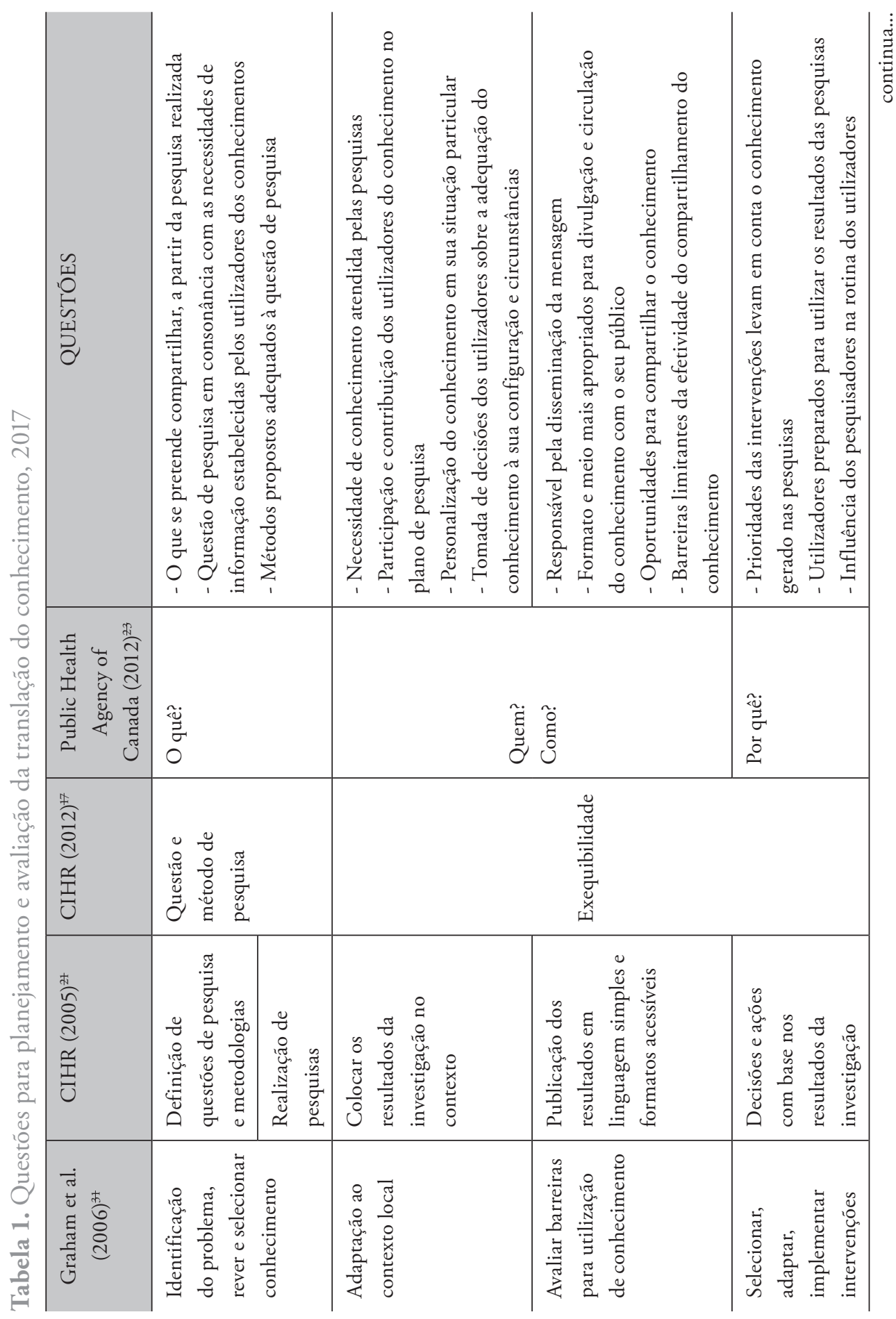


| Página 8 de 33

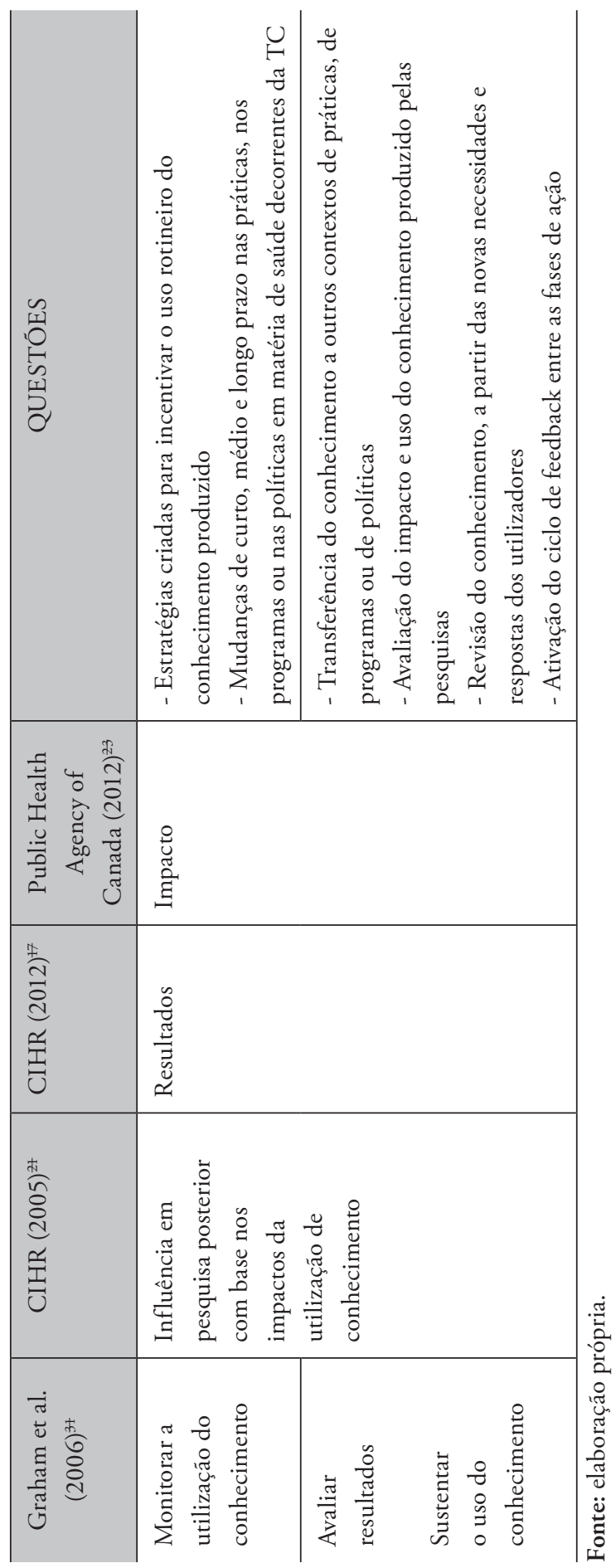


Para observar como o conhecimento produzido é realmente usado na prática, ou tentar encontrar provas documentais de TC, também foram analisados documentos produzidos nesse período, resultantes dos processos de formação: monografias, dissertaçôes e teses; apresentaçôes dos resultados das avaliações, produção técnica e científica.

Para a análise da ocorrência da TC nas pesquisas avaliativas realizadas por gestores e técnicos da SEVS/PE, adaptou-se o modelo KTA proposto por Graham et al. (2006), começando pela criação de conhecimento nas pesquisas, desde a investigação, passando pela síntese, até se tornar ferramentas ou produtos. Depois, detalhando o "Ciclo de Açáo" com as fases necessárias à aplicação do conhecimento produzido. As fases podem ocorrer sequencial ou simultaneamente, e ser realizadas por diferentes atores (criadores e utilizadores). Por se tratarem de estudos avaliativos, a esse modelo sobrepôs-se a estrutura teórica do uso-influência da avaliação, proposto por Hartz et al. (2008), que analisa tanto a influência da avaliação em diferentes dimensôes e níveis, quanto o tipo de uso da avaliação, captando as mudanças provocadas pelo processo e/ou resultados da avaliação, a depender do contexto da intervenção. A figura 1 explicita a relação entre a teoria do uso-influência com as fases do Ciclo de Ação do KTA.

$\mathrm{Na}$ matriz de análise, o conteúdo das falas dos entrevistados foi categorizado em cada fase do ciclo do conhecimento-ação e classificado no que se refere aos níveis e dimensôes da influência e ao tipo de uso observado.

Figura 1. Ciclo do conhecimento-ação, usos e influência da avaliaçấo, 2018

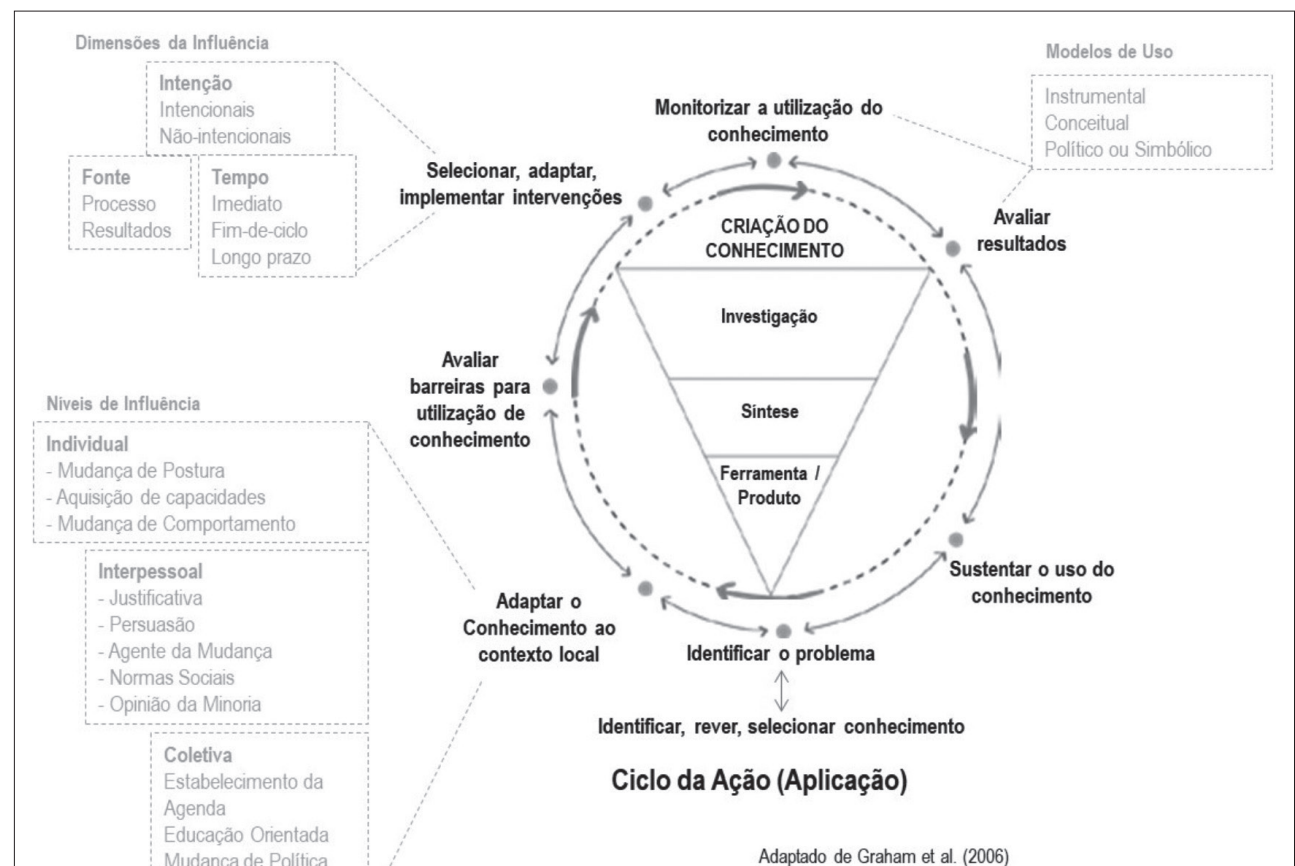


O presente estudo foi aprovado pelo Comitê de Ética em Pesquisa do Instituto de Medicina Integral Prof. Fernando Figueira (IMIP), parecer no 1.998.710, de 4 de abril de 2017, conforme protocolo 62352616.8.0000.5201.

\section{Resultados}

Os resultados são apresentados numa matriz de análise da translação do conhecimento, na qual o conteúdo das entrevistas e da apreciação dos documentos foi organizado com base nas fases ideais do modelo conhecimento para ação (KTA), e categorizado nas dimensōes e níveis do modelo de uso e influência da avaliação. Além do conteúdo da matriz de análise, falas de alguns entrevistados foram citadas, a fim de ilustrar os achados.

Na primeira fase, Identificar o problema, rever e solucionar o conhecimento relevante para o problema existente, constatou-se que os objetos de todas as avaliaçóes foram definidos conjuntamente, pelos pesquisadores, que eram gestores ou técnicos da Vigilância em Saúde, e pela equipe das áreas técnicas que eles integravam. Esse processo considerou os problemas prioritários discutidos entre eles e, portanto, a necessidade de conhecimento para solucioná-los no serviço, que foi atendida pelas pesquisas, com exceção da P8, que considerou os resultados encontrados contraditórios à realidade observada nas Gerências Regionais de Saúde, no que se refere à resposta às emergências em Saúde Pública (Tabela 2).

[...] O produto das pesquisas do mestrado foi pensado em conjunto com a equipe da área técnica do objeto de avaliação para seu resultado ser utilizado no serviço (D1).

$\mathrm{Na}$ fase de Adaptação do conhecimento ao contexto local, foram estabelecidas conexôes com os níveis de influência da avaliação (individual, interpessoal e coletiva). A contribuição dos utilizadores do conhecimento no desenho dos estudos e/ou dos modelos lógicos das intervenções estudadas foi o evento mais frequente que evidenciou a influência individual e interpessoal das pesquisas nesta etapa. A mudança de postura e disponibilidade das equipes para mudanças no processo de trabalho, a aceitação das recomendações propostas pela pesquisa e a possibilidade de críticas mais refinadas aos objetos estudados (WORLD HEALTH ORGANIZATION, 2005) foram também exemplos da influência individual e interpessoal na adaptação do conhecimento ao contexto. A viabilização de recursos financeiros e pessoal, e 
as mudanças nos formatos de reuniôes foram resultados da influência coletiva do conhecimento produzido (Tabela 2).

Os estudos não são meramente acadêmicos, porque são feitos por pessoas do serviço, que trazem além do conhecimento tácito a possibilidade de ter incorporado com uma metodologia validada, qualificada. Outra vantagem é a clareza com que eles são apresentados, que é para tentar fazer a mudança da realidade (D2).

Quando o estudo é feito por profissionais de dentro do setor tem mais chance de incorporar seus resultados (D3).

$\mathrm{Na}$ avaliação das barreiras pra utilização do conhecimento, a maior parte das pesquisas foi compartilhada com as respectivas áreas técnicas do nível central, porém apenas uma parte delas teve o compartilhamento ampliado para o nível regional. Sete das pesquisas foram apresentadas para turmas de especialização e mestrado, três foram apresentadas no maior evento nacional de vigilância em saúde (ExpoEpi) e quatro foram publicadas em revistas científicas ou como capítulo de livro. A principal barreira citada foi a falta de tempo, pela rotina exaustiva do serviço. Outros entraves estiveram relacionados à mudança do gestor do serviço, à desmotivação pela divergência entre os resultados da pesquisa e a realidade observada ou pela complexidade do modelo de análise utilizado (Tabela 2). A visão dos outros entrevistados integrantes das equipes com relação às barreiras para utilização do conhecimento foi mais abrangente, ao abordarem as parcerias e as emergências em saúde pública:

[...] é uma barreira ter que fazer muita coisa em pouco tempo e com pouca gente. Outra barreira é a dificuldade de ter parceria com outras áreas necessárias, como a atenção à saúde (D1).

[...] o que move a gestão mais que qualquer estudo avaliativo é o que surge como problema grande (ex. as epidemias). Usar de forma sistemática os estudos era meu desejo, mas não conseguimos. As meninas fizeram os estudos, mas quando voltaram tivemos outras coisas importantes para resolver (...) estamos sempre sem conseguir dar conta do importante, porque tem que dar conta do urgente (Ger. 1).

[...] outra fragilidade é que nem tudo pode ser aplicado, porque está fora da governabilidade ou porque temos muitas prioridades a serem atendidas (Ger. 3).

$\mathrm{Na}$ seleção, adaptação e implementação de intervençôes, a interface foi feita com as dimensôes da influência (intençáo, fonte e tempo). A reformatação ou instituição de reuniôes; o estabelecimento de agendas de educação permanente; a alteração de fluxos; a ampliação/adequação de açóes; e a elaboração/publicaçáo de 
manuais, instrumentos e informes foram evidências que caracterizaram a influência intencional, a partir dos resultados, no fim do ciclo das avaliaçōes. A contratação de uma das pesquisadoras pelo Ministério da Saúde foi classificada na dimensão não intencional da influência. O reforço/remanejamento no quadro de profissionais e o estabelecimento de parceria com universidade se enquadraram na influência de longo prazo (Tabela 2). As falas dos outros integrantes das equipes tiveram um foco no nível interpessoal da influência:

[...] influenciar outros profissionais depende de quem fez a avaliação, há uma subjetividade, não é uma rotina institucional como deveria ser (D3).

[...] as pessoas tentam influenciar outras e é isso que ajuda a cultura de avaliação se manter na SEVS (D2).

[...] os pesquisadores tentam influenciar, já que levam os resultados para dentro da sua área técnica e nesta, nem todos tinham participado da construção do estudo (D4).

Na P8 não houve aplicação do conhecimento que resultasse na seleção, adaptação ou implementação de intervençôes. Problemas metodológicos podem ter gerado resultados divergentes do esperado e do que é observado na prática das Geres, o que desmotivou o compartilhamento e o uso do estudo, conforme relato da pesquisadora. 


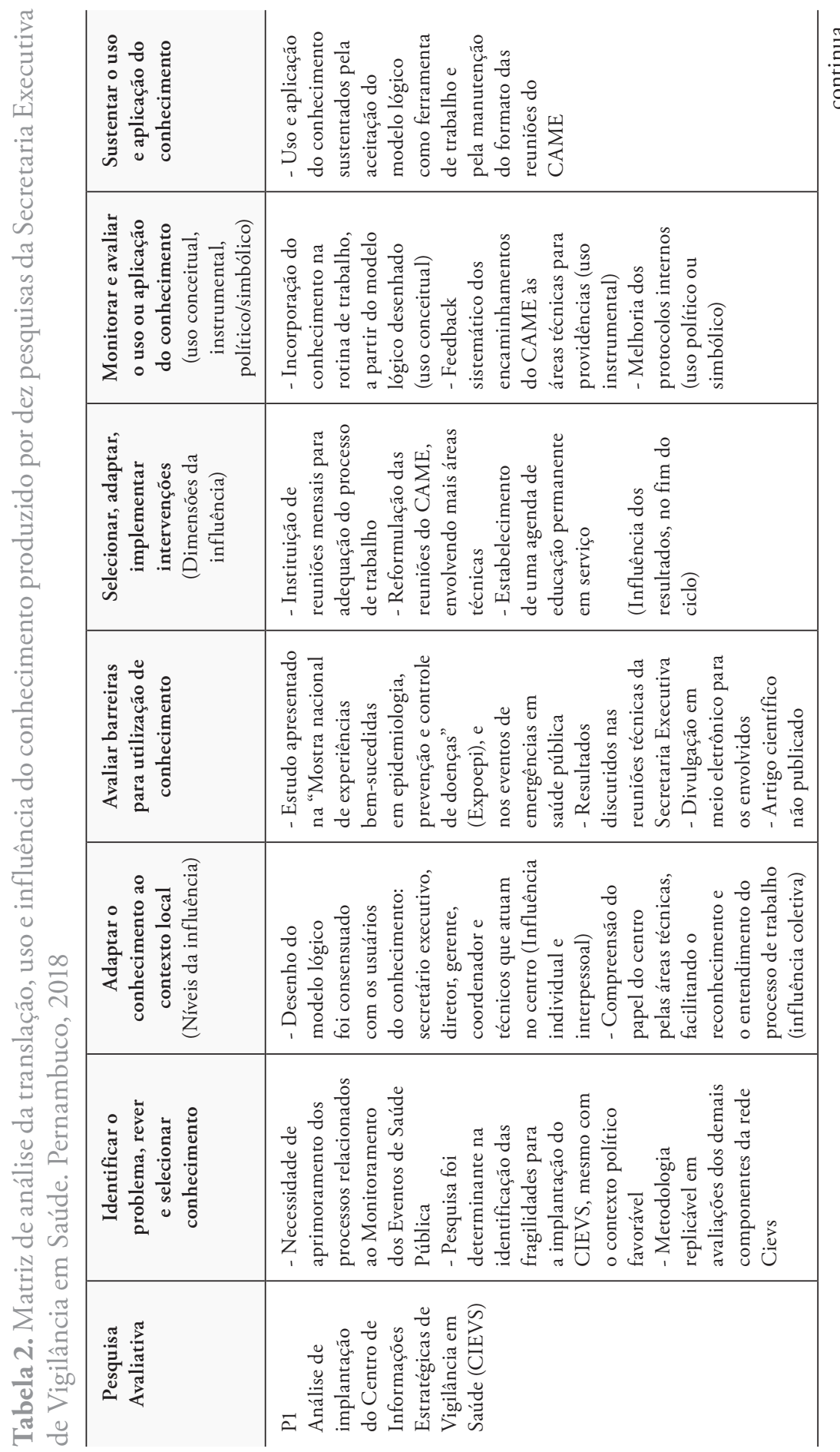




\begin{tabular}{|c|c|}
\hline 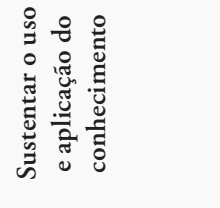 & 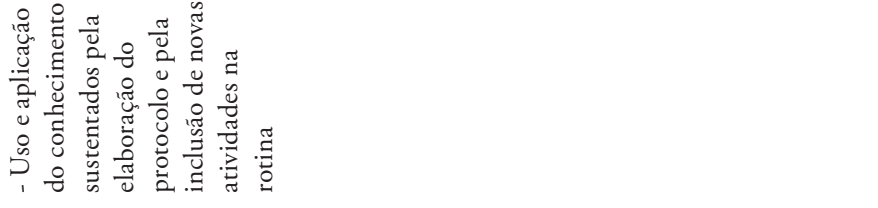 \\
\hline 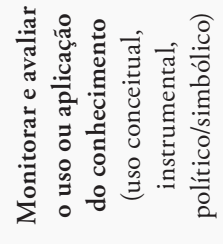 & 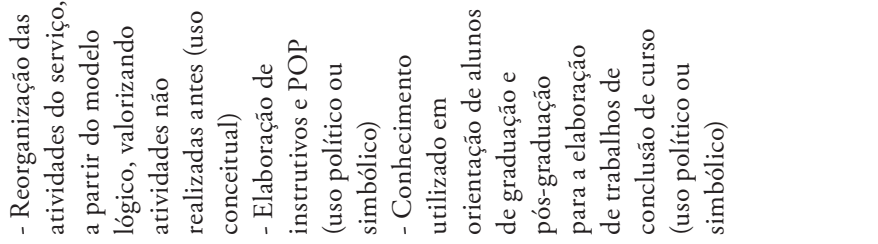 \\
\hline 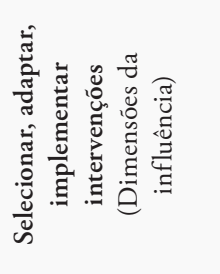 & 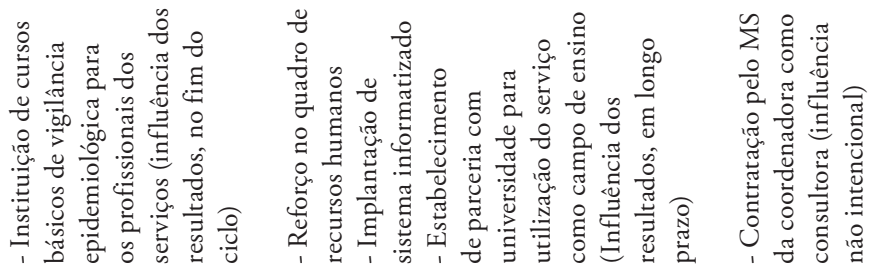 \\
\hline 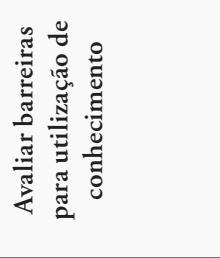 & 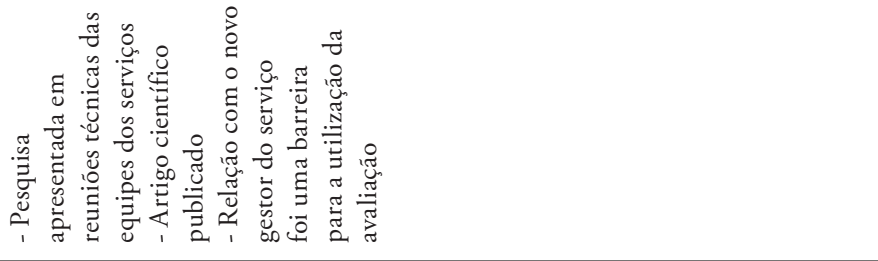 \\
\hline 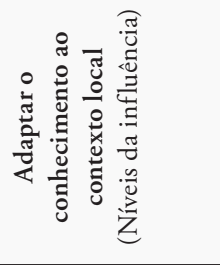 & 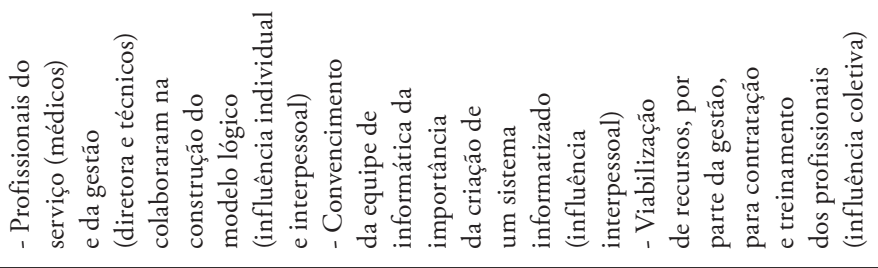 \\
\hline 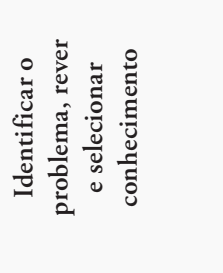 & 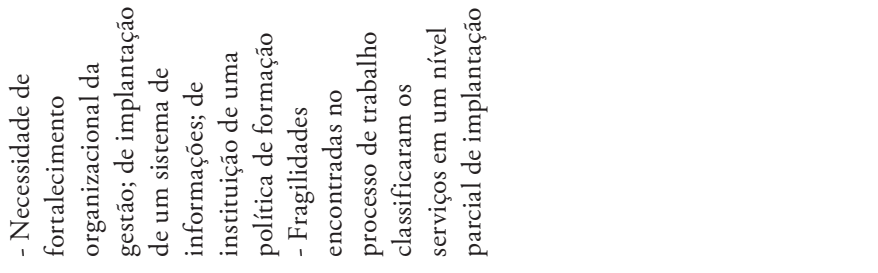 \\
\hline 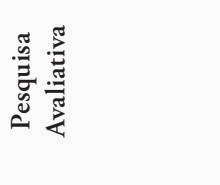 & 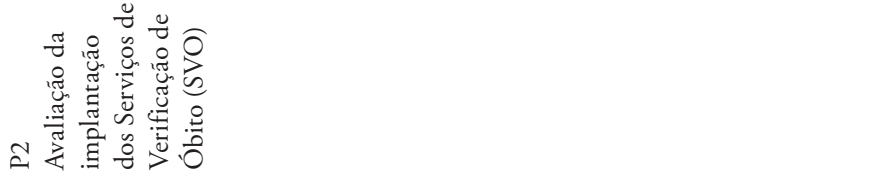 \\
\hline
\end{tabular}




\begin{tabular}{|c|c|}
\hline 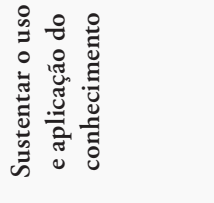 & 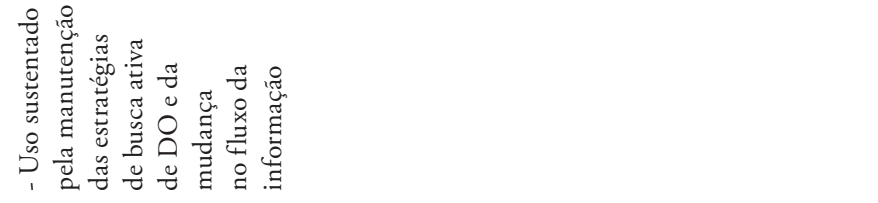 \\
\hline 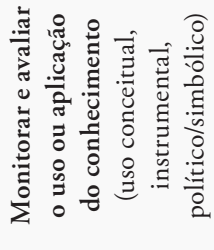 & 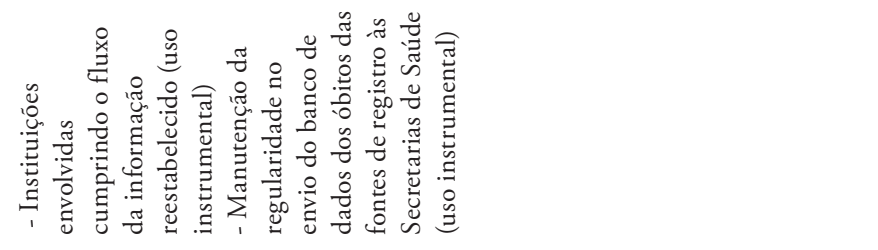 \\
\hline 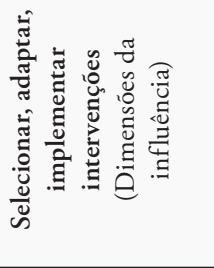 & 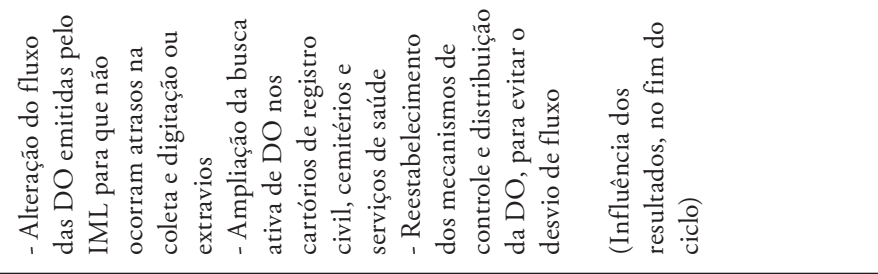 \\
\hline 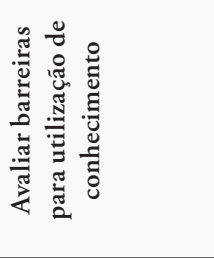 & 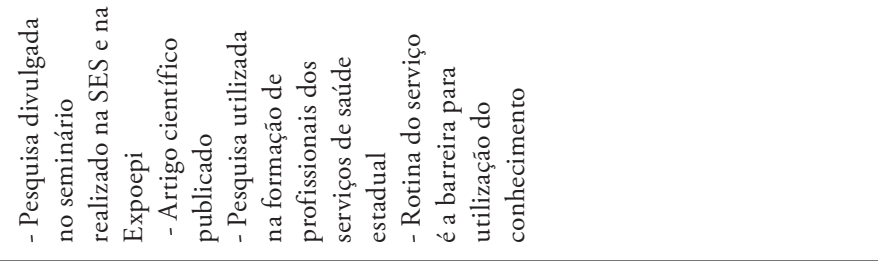 \\
\hline 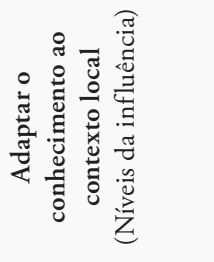 & 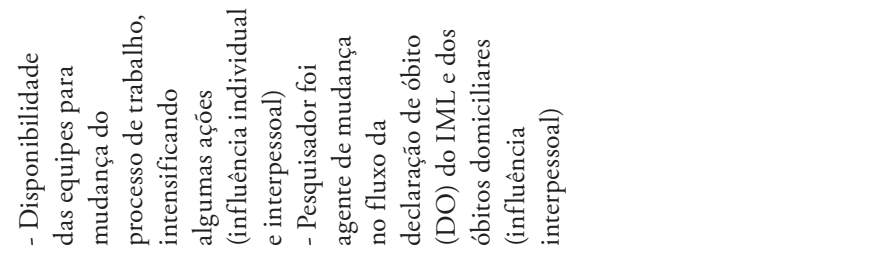 \\
\hline 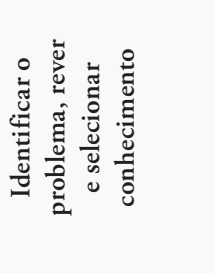 & 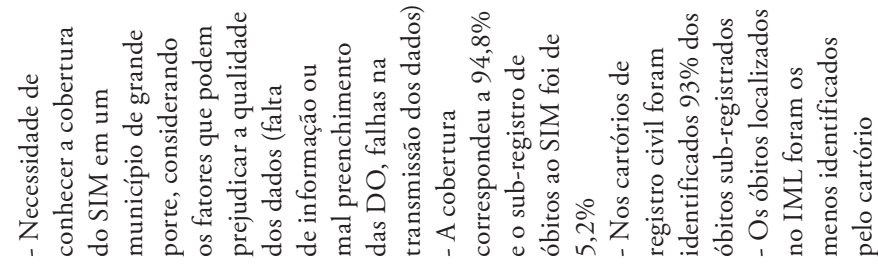 \\
\hline 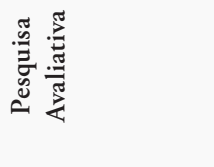 & 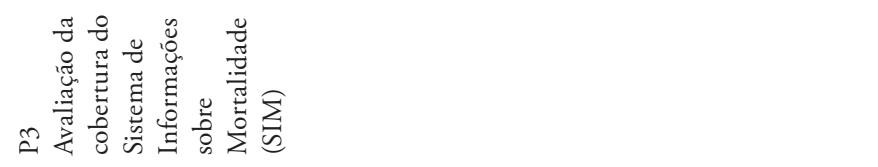 \\
\hline
\end{tabular}




\begin{tabular}{|c|c|}
\hline 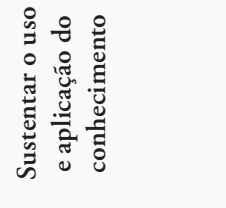 & 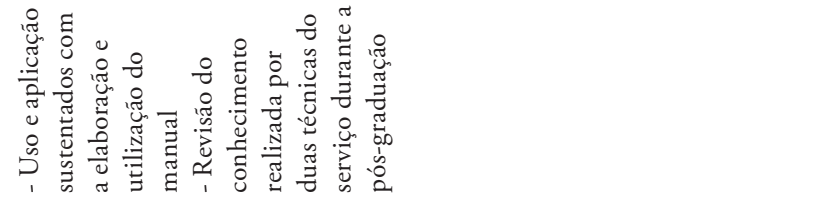 \\
\hline 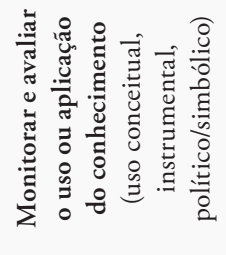 & 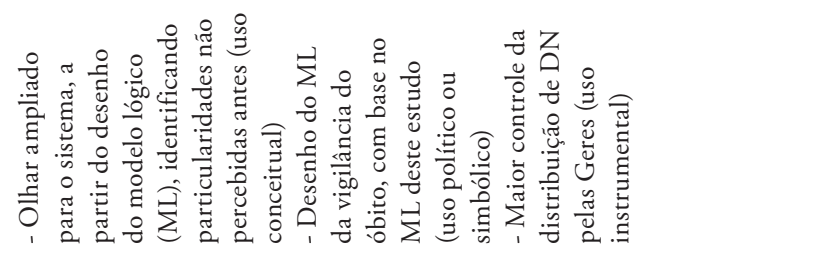 \\
\hline 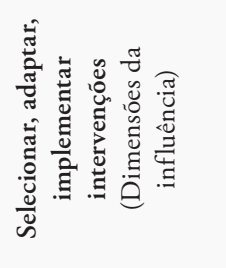 & 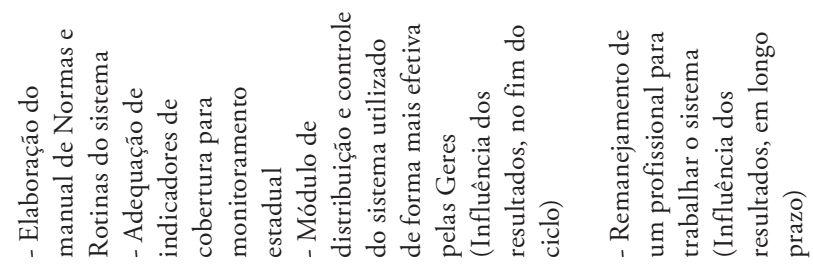 \\
\hline 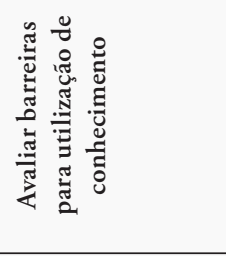 & 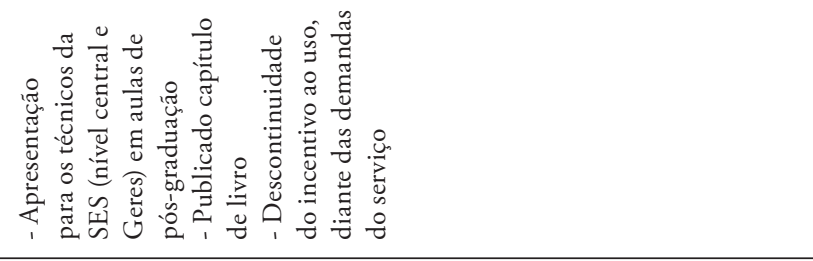 \\
\hline 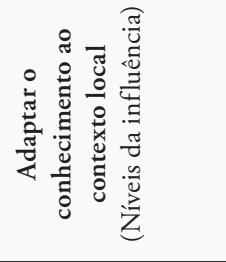 & 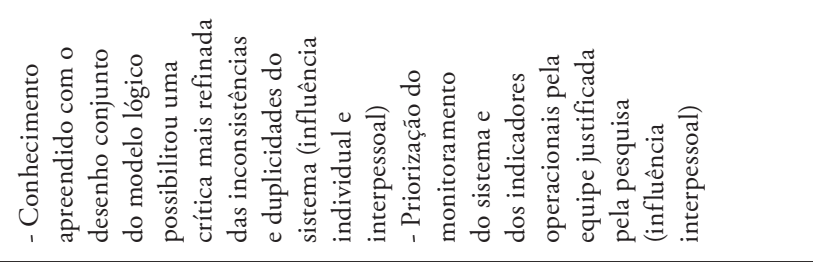 \\
\hline 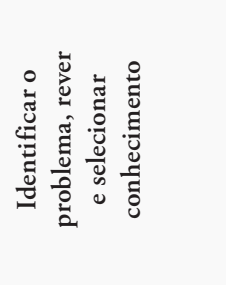 & 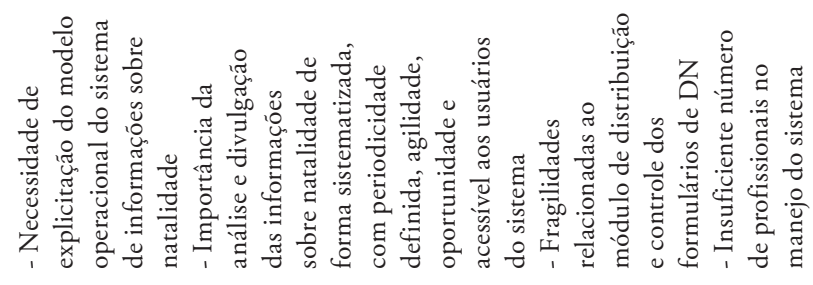 \\
\hline 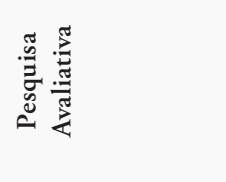 & 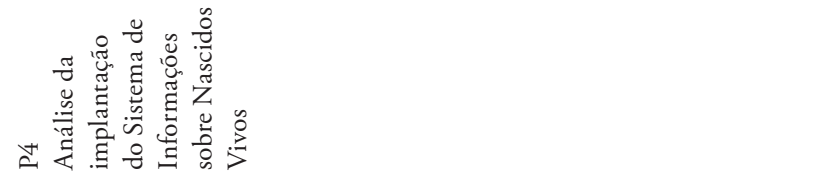 \\
\hline
\end{tabular}




\begin{tabular}{|c|c|}
\hline 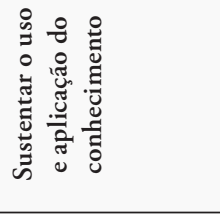 & 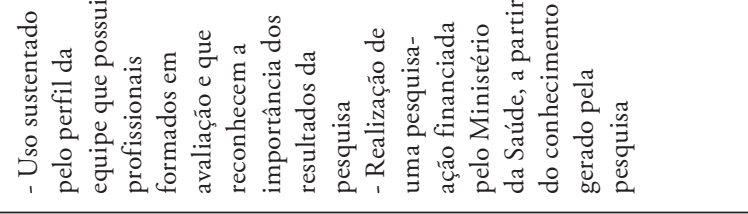 \\
\hline 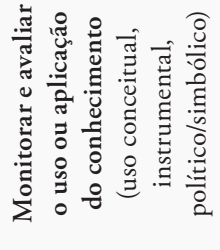 & 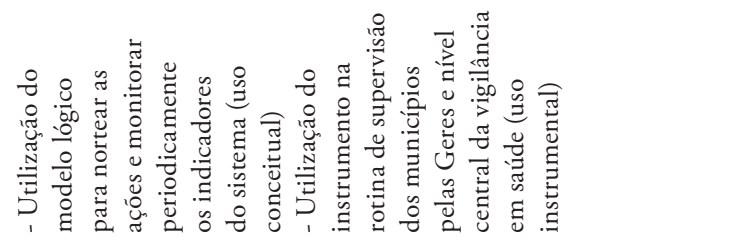 \\
\hline 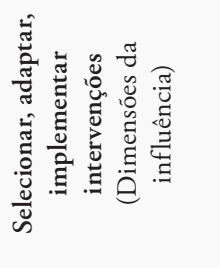 & 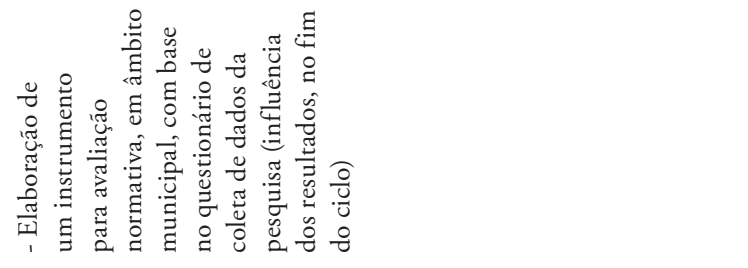 \\
\hline 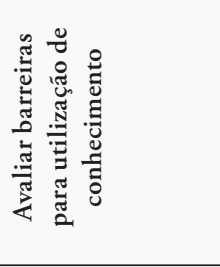 & 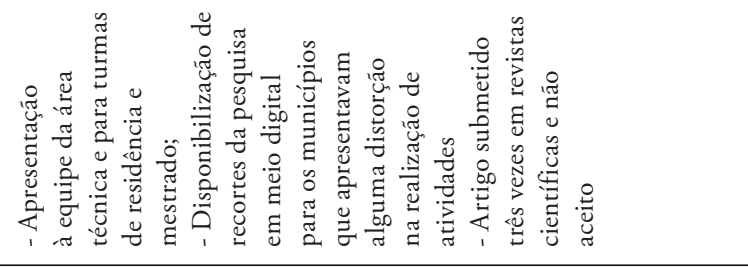 \\
\hline 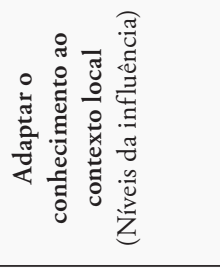 & 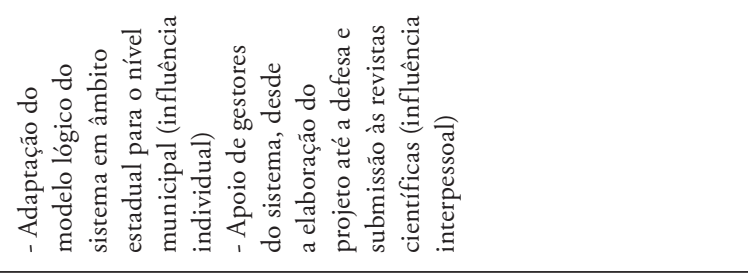 \\
\hline 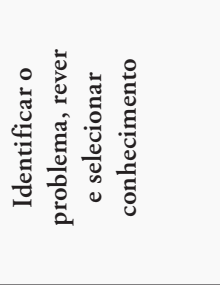 & 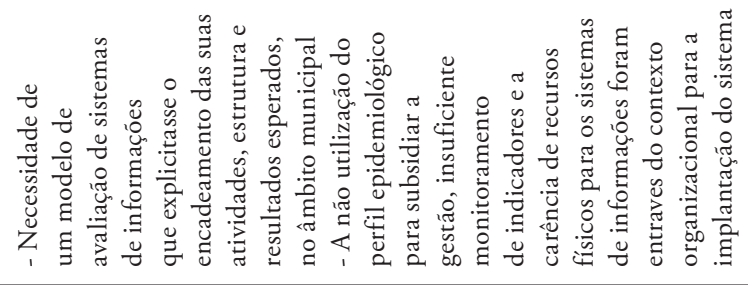 \\
\hline 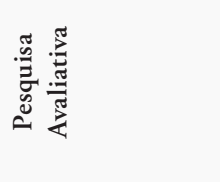 & 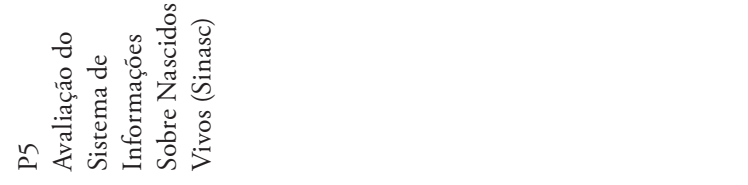 \\
\hline
\end{tabular}




\begin{tabular}{|c|c|}
\hline 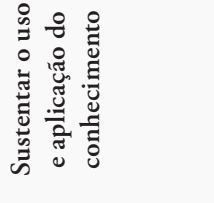 & 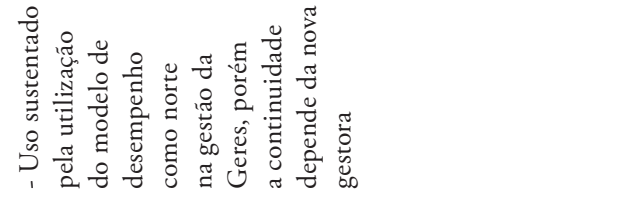 \\
\hline 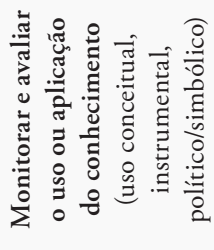 & 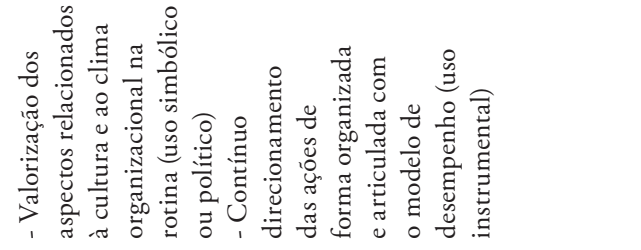 \\
\hline 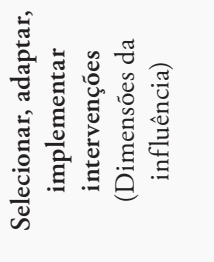 & 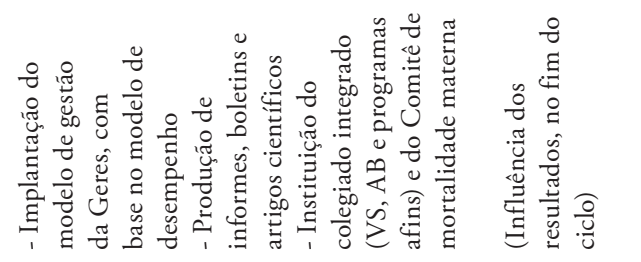 \\
\hline 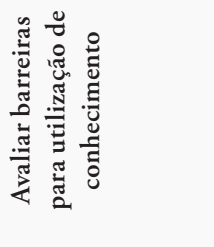 & 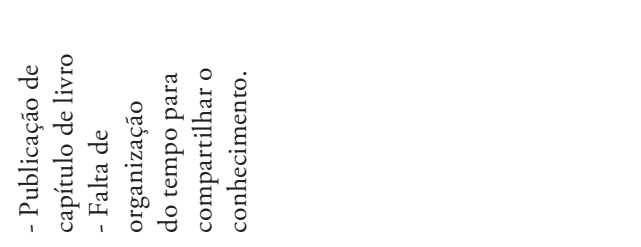 \\
\hline 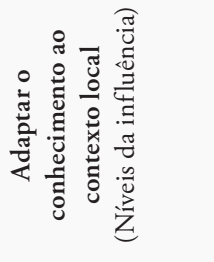 & 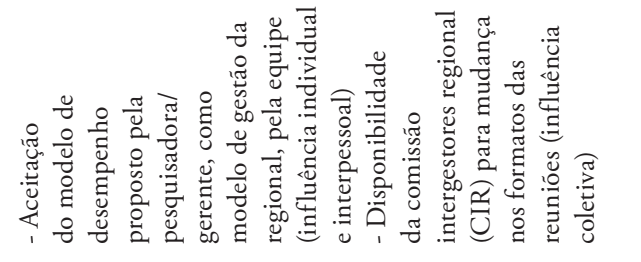 \\
\hline 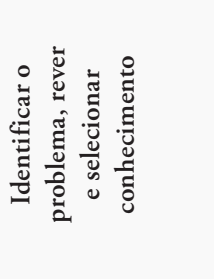 & 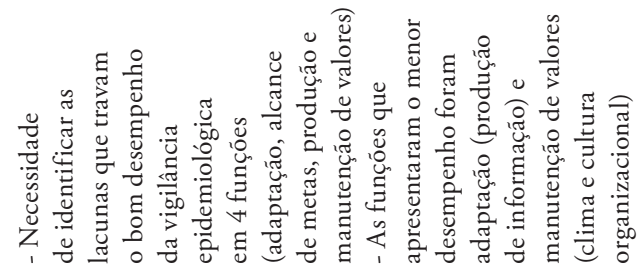 \\
\hline 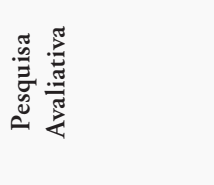 & 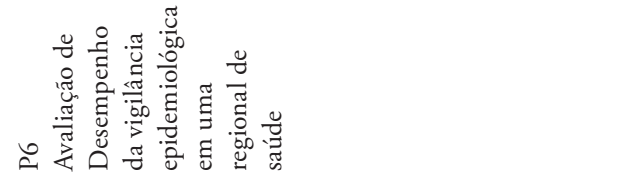 \\
\hline
\end{tabular}




\begin{tabular}{|c|c|}
\hline 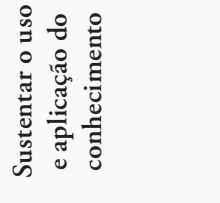 & 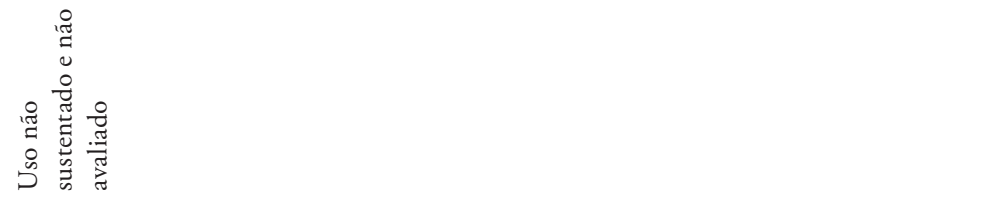 \\
\hline 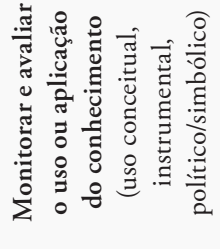 & 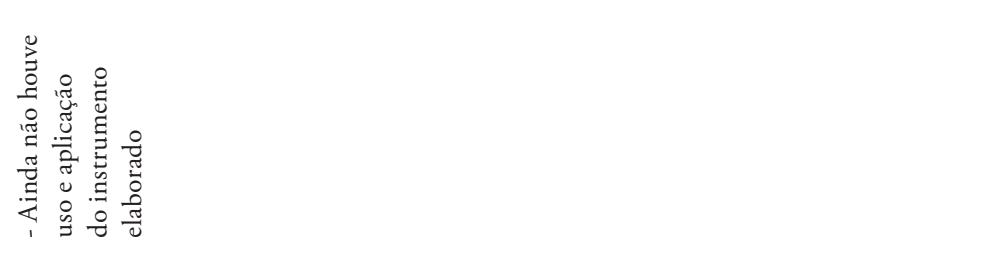 \\
\hline 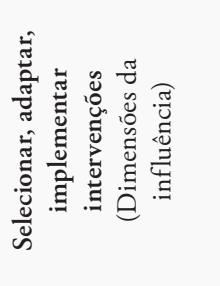 & 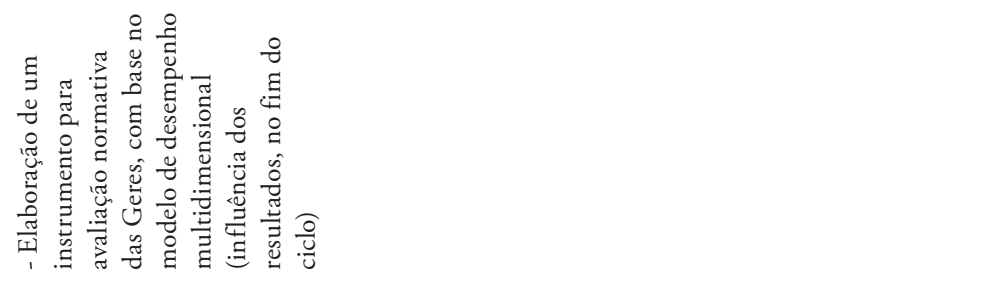 \\
\hline 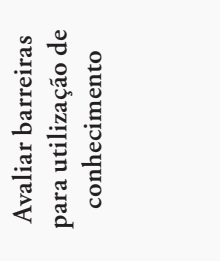 & 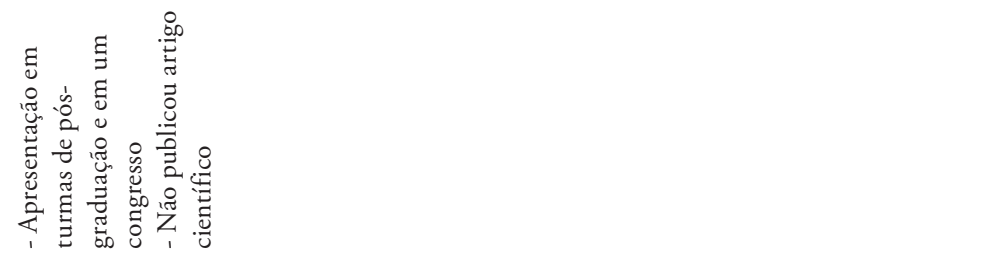 \\
\hline 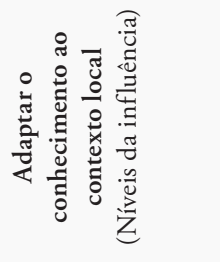 & 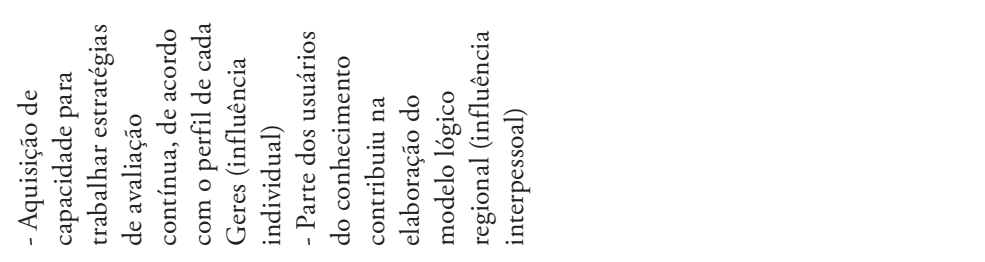 \\
\hline 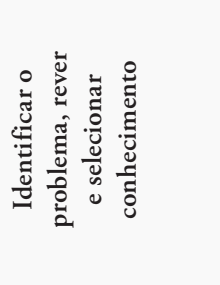 & 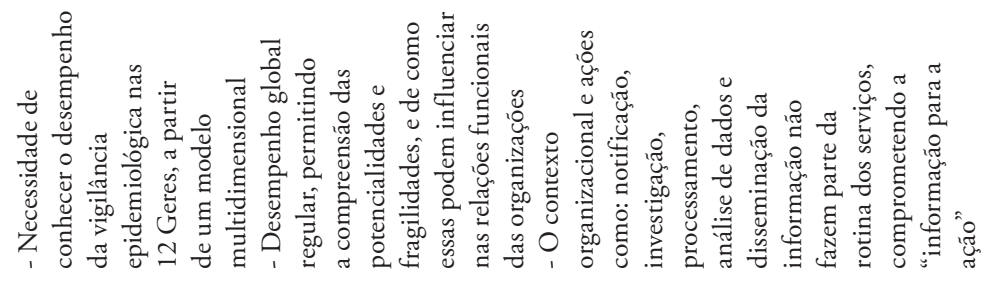 \\
\hline 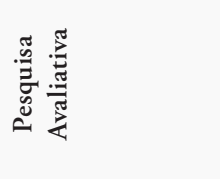 & 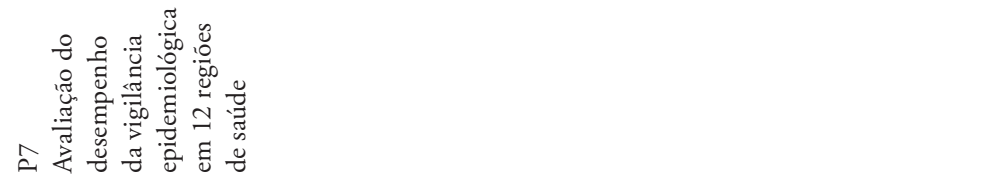 \\
\hline
\end{tabular}




\begin{tabular}{|c|c|}
\hline 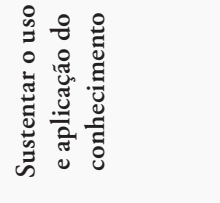 & 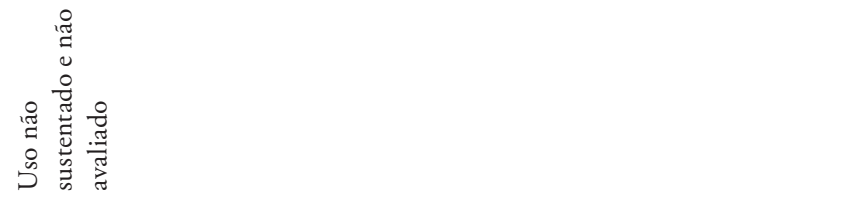 \\
\hline 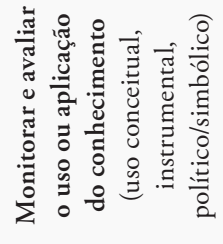 & 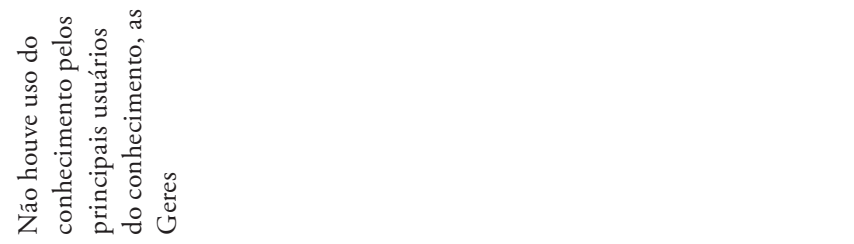 \\
\hline 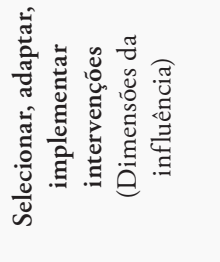 & 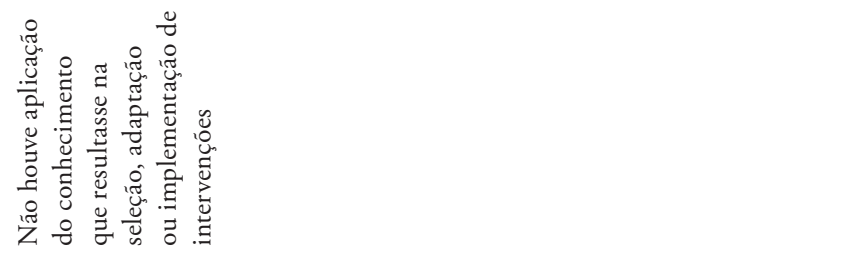 \\
\hline 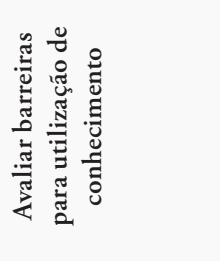 & 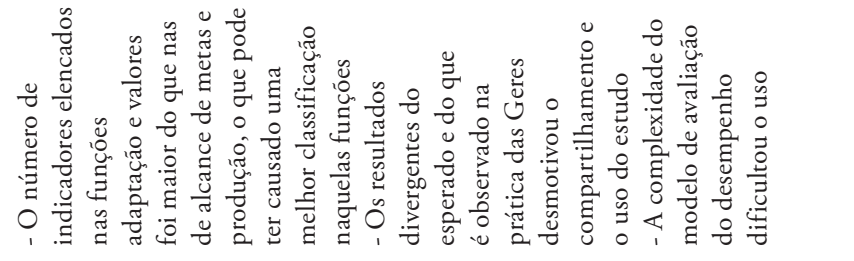 \\
\hline 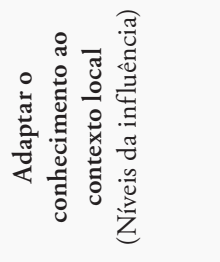 & 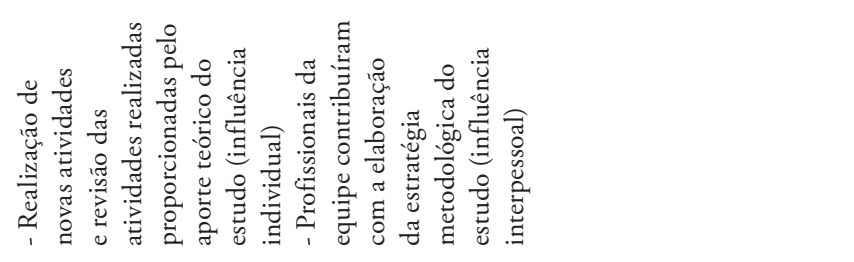 \\
\hline 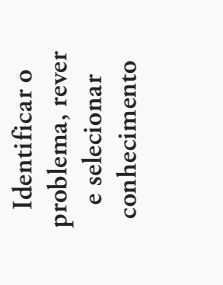 & 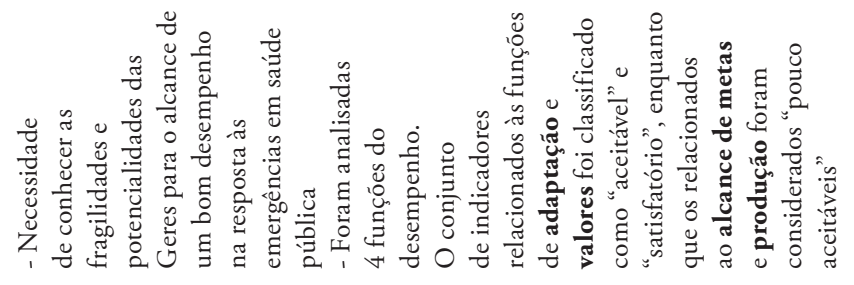 \\
\hline 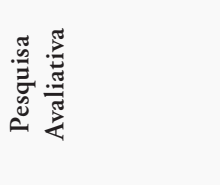 & 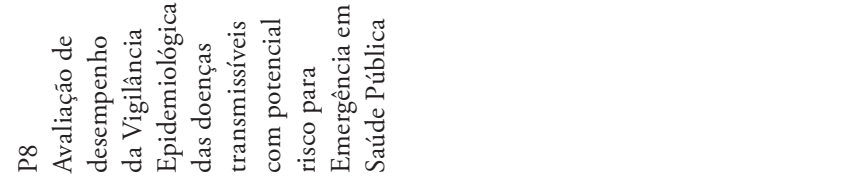 \\
\hline
\end{tabular}




\begin{tabular}{|c|c|}
\hline 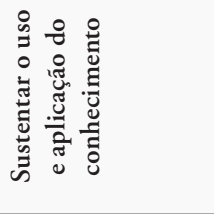 & 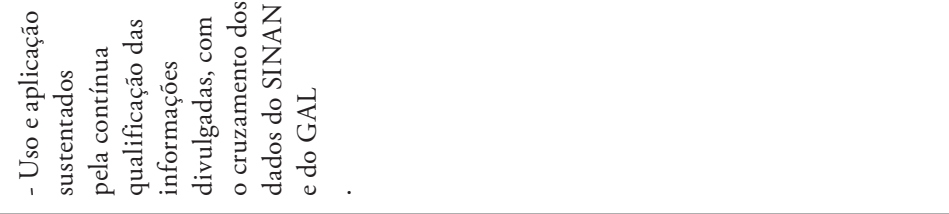 \\
\hline 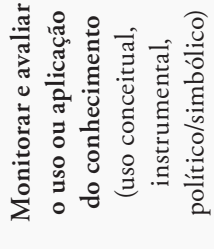 & 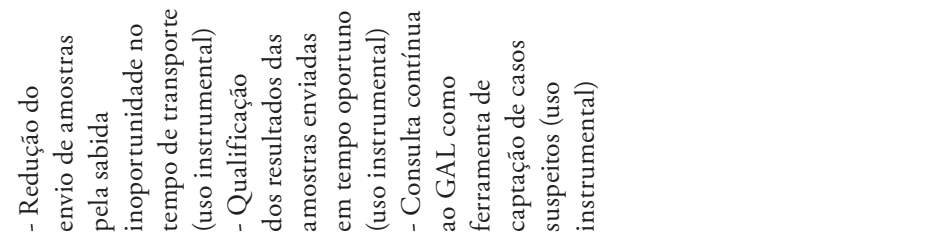 \\
\hline 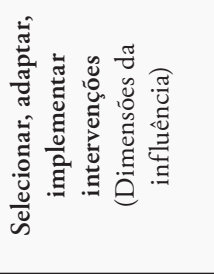 & 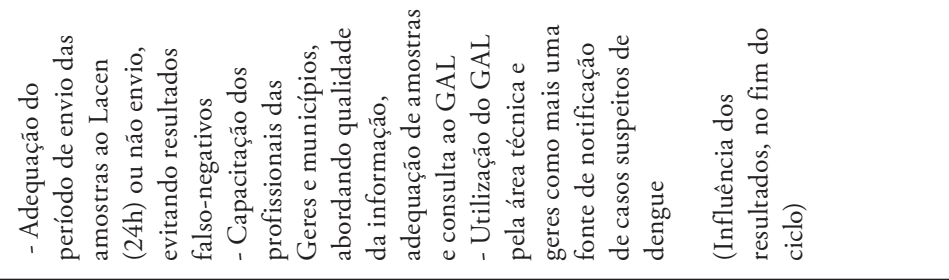 \\
\hline 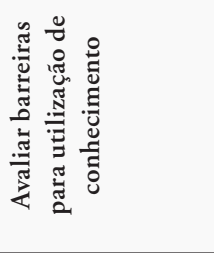 & 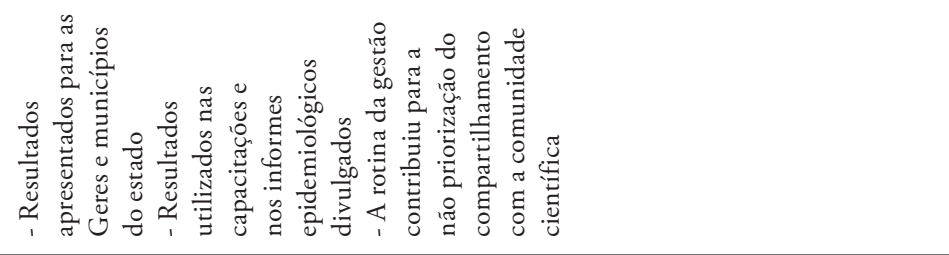 \\
\hline 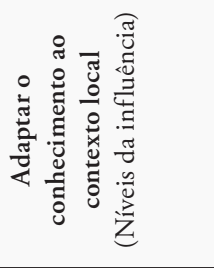 & 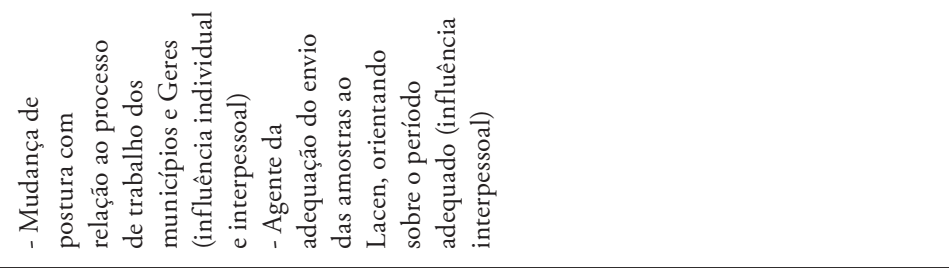 \\
\hline 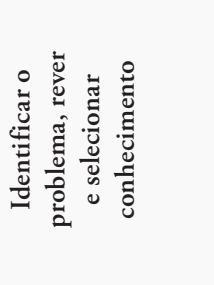 & 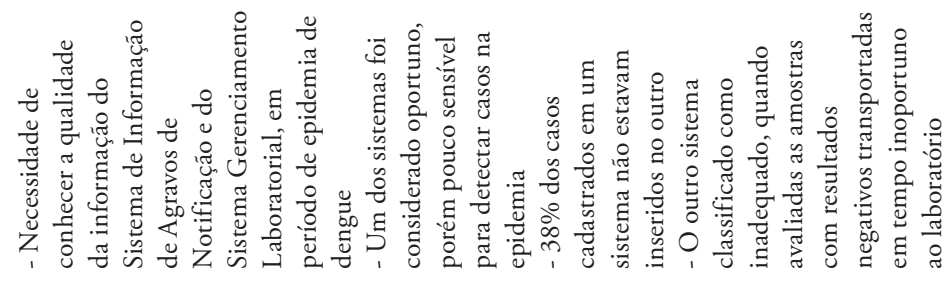 \\
\hline 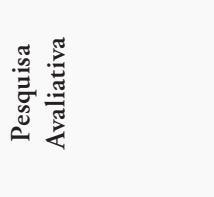 & 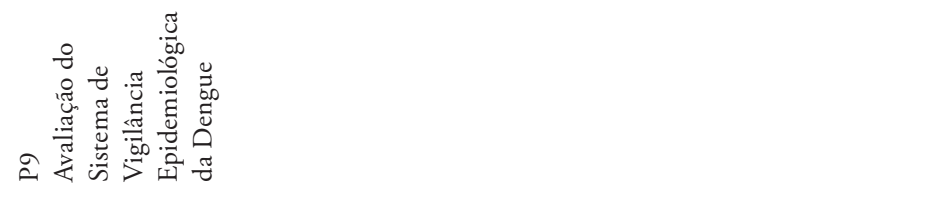 \\
\hline
\end{tabular}




\begin{tabular}{|c|c|}
\hline 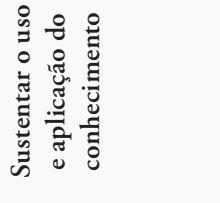 & 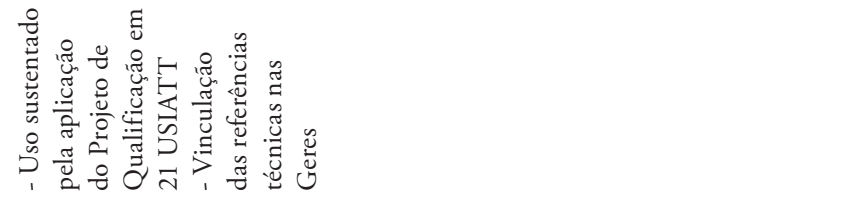 \\
\hline 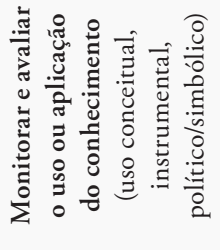 & 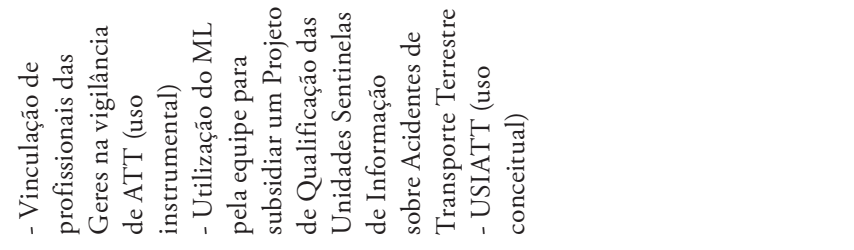 \\
\hline 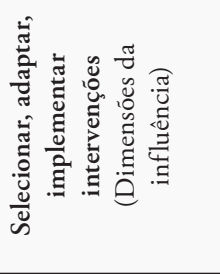 & 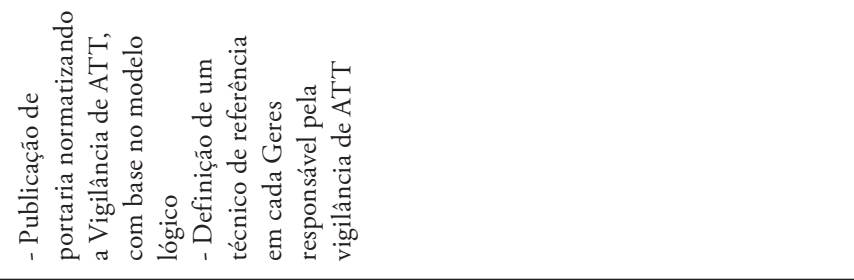 \\
\hline 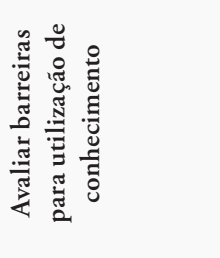 & 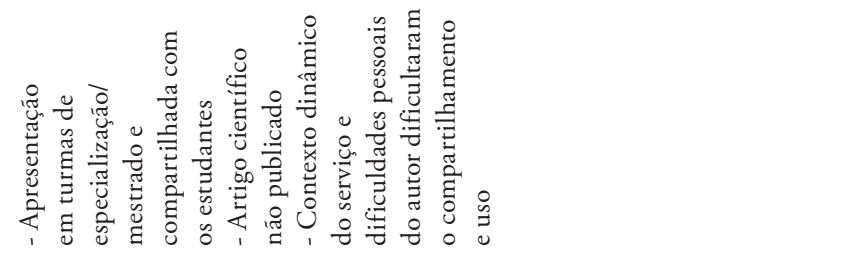 \\
\hline 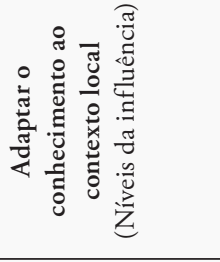 & 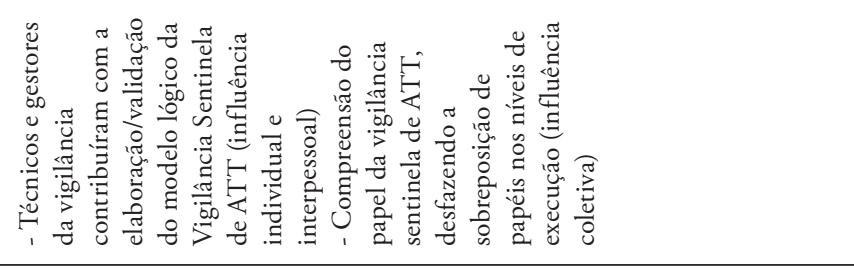 \\
\hline 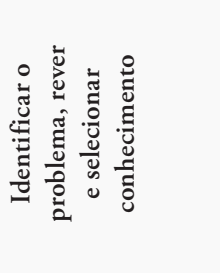 & 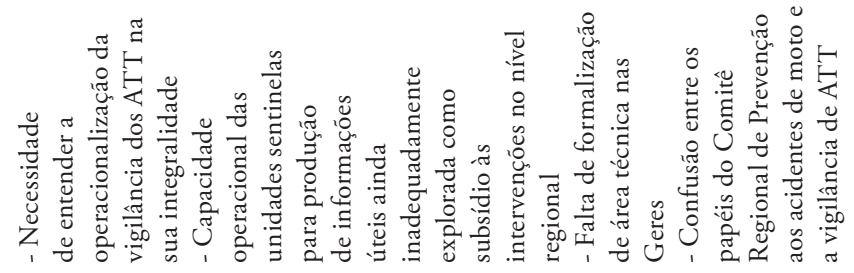 \\
\hline 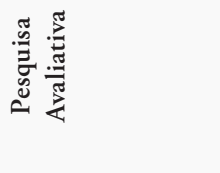 & 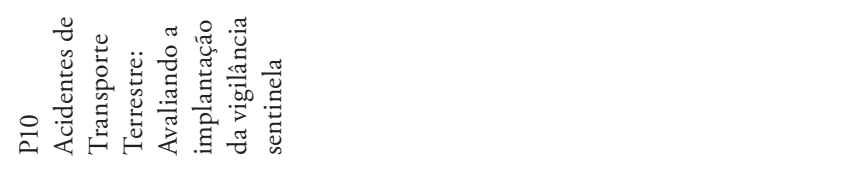 \\
\hline
\end{tabular}


Nas etapas de Monitoramento e avaliação do uso ou aplicação do conhecimento, foram analisadas as mudanças ocorridas com base nas intervençôes implementadas, a partir dos três tipos de uso (instrumental, político/simbólico e conceitual). Em cinco das pesquisas (P1, P2, P4, P5 e P10), o uso conceitual da teoria da intervenção representada pelos modelos lógicos desenhados pelos pesquisadores e suas equipes possibilitou a ampliação do olhar de todos sobre seus componentes e a reorganização/ orientação das açôes e do monitoramento. A evidência da avaliação foi utilizada instrumentalmente para tomar algumas decisões, por exemplo, a equipe do CIEVS envia sistematicamente os encaminhamentos do CAME às áreas técnicas envolvidas para providências; no SIM, as fontes de registro atualizam as Secretarias de Saúde rotineiramente com seu banco de dados dos óbitos; no Sinasc, houve um maior controle da distribuição de declaração de nascidos vivos pelas Geres, dentre outras. Simbolicamente, as avaliações foram utilizadas para legitimar posiçôes e formular diretrizes, como na melhoria de protocolos, elaboração de instrutivos; orientação de alunos de graduação e pós; valorização de aspectos antes não valorizados na gestão regional, como cultura e clima organizacional (Tabela 2). Os entrevistados integrantes das áreas tiveram percepçôes distintas a respeito das mudanças ocorridas:

[...] como a maioria dos estudos era de implantação, viram as lacunas que tínhamos no sistema, muito mais do que imaginávamos, e hoje temos cursos que tentam capacitar as pessoas para que elas fechem essas lacunas. (D1).

[...] a partir de 2 estudos aqui da nossa área, foram feitas mudanças de curto prazo. As mestrandas ajudaram a reestruturar o processo de trabalho dos programas avaliados [...] (D2).

[...] acho que poucas mudanças, principalmente de médio e longo prazo, até porque pouco conhecemos os estudos produzidos, a devolutiva ou até que ponto usou foi pouco divulgado na SEVS em geral, não sei dentro de cada área técnica (Ger. 2).

Na última fase, Sustentar o uso do conhecimento, de certa forma, a manutenção das intervençóes implementadas pelo conhecimento utilizado e aplicado, a partir das pesquisas, sustentou o seu uso; seja pelo perfil dos profissionais da equipe formados na área de avaliação, seja pelo envolvimento da equipe no desenho dos modelos lógicos ou, ainda, pela necessidade das mudanças constatadas pelas pesquisas realizadas. No que se refere ao ciclo de feedback entre as fases, colocado em movimento nesta etapa, a barreira citada por um dos pesquisadores, a não aceitação do artigo pelo periódico científico, fez com que ele fosse reformulado e submetido a mais dois periódicos, no sentido de promover a aceitação do conhecimento (Tabela 2). 
[...] geralmente, esses estudos de avaliaçấo do uso ficam restritos ao âmbito acadêmico, na gestáo não se tem conseguido nem dar conta do processo de monitoramento (Ger. 2).

[...] ter um fórum maior para apresentar os estudos (por exemplo, no ciclo de debates da SEVS), além de entregar os resultados por escrito, seriam ótimas estratégias. Também, cada diretoria pegar o resultado e sistematizar de forma que se incorporasse no monitoramento da gestấo como problema e na linha de prioridade de ação de cada programa (Ger. 3).

\section{Discussão}

Muitos são os estudos que evidenciam as barreiras do acesso ao conhecimento produzido pelas pesquisas no campo das políticas de saúde, e mais outros tantos sugerindo estratégias para potencializar sua utilização, porém os desafios descritos na literatura parecem persistir (OLIVER; LORENC; INNVAER, 2014). Se a produção científica, via de regra, pouco reverbera para além do meio acadêmico, o processo de translação de novos conhecimentos gerados por avaliaçóes é ainda mais complexo, no que se refere à tríade: atitude dos avaliadores; envolvimento/ habilidade dos utilizadores; e os mecanismos organizacionais de suporte (BENNET et al., 2003; FIGUEIRÓ et al., 2012; GAGLIARD et al., 2016; HARTZ et al., 2008; HENRY; MARK, 2003; JOHNSON, 2005).

No caso das pesquisas avaliativas realizadas por profissionais da Secretaria Executiva de Vigilância do Estado de Pernambuco (SEVS/PE), a posição dos avaliadores (líderes de opiniáo e decisores) na equipe influenciou a percepção e a atitude dos usuários do conhecimento frente aos seus objetos de trabalho, que foram alvos das pesquisas, fazendo-os reconhecer as utilidades da avaliação. Influências intencionais (ex. compreensão dos modelos lógicos das intervençôes) e não intencionais (ex. contrataçáo da pesquisadora como consultora do MS); coletivas, interpessoais ou individuais, ocorreram, ainda que em intensidades e periodicidades diferentes (FIGUEIRÓ et al., 2012; HARTZ et al., 2008; HENRY; MARK, 2003). A cadeia de TC ativada pelas pesquisas avaliativas envolveu os utilizadores, em especial os que já tinham alguma familiaridade com a área de avaliação, constatando-se, mais uma vez, o que é unânime entre os autores: a importância do engajamento dos mesmos para o êxito da TC, ainda na fase de planejamento das pesquisas (GAGLIARD et al., 2016; CANADIAN INSTITUTES OF HEALTH RESEARCH, 2012; GRAHAM et al., 2006; JACOBSON; BUTTERILL; GOERING, 2003; VINGILIS et al., 2003). 
Além da definição conjunta dos problemas prioritários, as equipes participaram e contribuíram na elaboração dos modelos lógicos das intervençóes existentes para resolvê-los, gerando um conhecimento que, antes mesmo do julgamento de valor, tão esperado pelo avaliador, permitiu que o grupo compreendesse as intervençôes na sua dimensão unitária (objetivos, componentes, atividades, resultados esperados) e na interação entre suas partes (BEZERRA; CAZARIN; ALVES, 2010; CHAMPAGNE et al., 2011). Essa abordagem contextualizada, ou seja, alinhada com a expectativa do serviço, buscou superar a arbitrariedade semântica da avaliação, tanto no que diz respeito à reconstrução da teoria do objeto a ser avaliado, quanto ao próprio julgamento de valor. Mesmo nas pesquisas pouco ou não utilizadas e aplicadas, a proposição (semântica) esteve atrelada à interpretação, no contexto e com as partes interessadas (pragmática da avaliação), o que contribuiu para uma maior compreensão, aceitação e disposição para mudanças (ABREU et al., 2017; BEZERRA; CAZARIN; ALVES, 2010; FIGUEIRÓ et al., 2016; GAGLIARD et al., 2016; HARTZ, 2013; WEISS; MURPHY-GRAHAM; BIRKELAND, 2005).

O grau da translação (utilização e aplicação) do conhecimento alcançado principalmente pelos resultados, no fim do ciclo das avaliaçóes, após essa "influência inicial", dependeu, portanto, da identificação das oportunidades e superação das barreiras que se apresentaram; além da capacidade de compor as prioridades das áreas envolvidas para seleção, adaptação ou implementação de intervenções (HARTZ et al., 2008).

Como descrito na literatura, a principal barreira relatada para a TC foi a falta de tempo, consequente da rotina exaustiva do serviço que, anterior à utilizaçáo do conhecimento, dificultou a sua disseminação, difusão e compartilhamento (BENNET et al., 2003; DAVIS, 2005; GAGLIARD, 2016; MELINE; PARADISO, 2003). A falta de evidência relevante foi citada por uma das pesquisadoras como principal barreira (BENNET et al., 2003). O poder de persuasão do pesquisador traduzido pela sua disposição em reproduzir a mensagem em espaços distintos serviço, academia, meio científico - reverberou na adaptação e implementação de intervençôes, a partir do conhecimento gerado (WORLD HEALTH ORGANIZATION, 2005). Mudanças relacionadas ao conhecimento, atitudes, habilidades e hábitos foram proporcionadas.

Analisando-se a TC à luz das três premissas propostas por Oliver, Lorenc e Innvaer (2014) para o uso de evidências nas políticas de saúde, a estratégia utilizada 
pela Secretaria de Vigilância parece ser um dos caminhos para o sucesso da TC: (1) a ligação entre a evidência política e a adequada produção de conhecimento foi feita pelo pesquisador/decisor, de modo que atendeu às necessidades dos serviços; (2) a avaliação participativa utilizada pela maioria das pesquisas contribuiu para um maior envolvimento dos utilizadores, inclusive no processo; e (3) as mudanças proporcionadas pelos resultados das pesquisas foram capazes de demonstrar os benefícios das avaliaçôes (readequaçóes dos processos de trabalho, elaboração de material instrutivo, qualificação das ações, dentre outras).

Embora avaliaçôes sobre a efetividade da aplicação do conhecimento em termos de resultados no sistema de saúde não tenham sido realizadas, a compreensão dos pesquisadores do que poderia influenciar as práticas nos serviços de saúde e a tomada de decisão foram determinantes na ressignificação e valorização das pesquisas para dentro das equipes (ABREU et al., 2017; OLIVER; LORENC; INNVAER, 2014). A ocorrência dos usos conceitual, instrumental e político/simbólico demonstrou que o aumento da capacidade avaliativa dos pesquisadores, por si só, favoreceu uma gama de melhorias sistemáticas e contínuas, na medida em que o conhecimento produzido influenciou e foi incorporado à rotina dos serviços; contribuiu para a reorganização e qualificação de atividades; e forneceu subsídios para a elaboração de material instrutivo e protocolos.

Ainda que algumas evidências tenham apontado para o uso e aplicação sustentados do conhecimento (revisita aos modelos lógicos, atualização de protocolos, manutenção dos fluxos), o planejamento de fatores relevantes à sustentabilidade da TC e essenciais às mudanças de práticas não foi contemplado nos projetos das pesquisas (DAVIES; EDWARDS, 2013; OELKE; LIMA; ACOSTA, 2015). O ideal é que barreiras sejam ponderadas para a retenção das mudanças de práticas e que haja uma sistemática utilização dos resultados da investigação, refletindo sobre a forma como as mudanças podem ser mantidas e ampliadas para outras áreas e quais fatores contextuais facilitarão a manutenção e o futuro da TC (OELKE; LIMA; ACOSTA, 2015).

Duas das avaliaçôes analisadas neste estudo não foram utilizadas ou aplicadas e, portanto, nem os processos de mudança de atitudes, crenças e açôes, os quais a avaliaçáo afeta, nem os resultados intermediários que ocorrem entre a pesquisa e as melhorias sociais foram suficientemente desenvolvidos (HENRY; MARK, 2003). Dentre os três princípios básicos da TC: conhecimento, diálogo e capacidade (BENNET; JESSANI, 2011), uma das pesquisas, de início, já não cumpriu com o 
primeiro, ou seja, não obteve uma base de conhecimento robusta e contextualizada, o que inviabilizou a translação. No outro estudo, embora tenha produzido um conhecimento validado, o diálogo/troca regulares e o desenvolvimento de habilidades para responder às oportunidades de TC não foram relatados.

De acordo com Bennet e Jessani (2011), existem quatro modelos de TC:

1) Modelo "push": em que o pesquisador é o principal promotor da mudança, por meio de ferramentas adequadas, considerando os contextos e pressôes políticas para os receptores do conhecimento.

2) Modelo "pull”: em que os usuários das pesquisas e tomadores de decisão solicitam à academia as informaçóes, as evidências e os pesquisadores com a habilidade que eles acham que precisam.

3) Modelo "exchange": baseia-se em parcerias entre pesquisadores e utilizadores da pesquisa que colaboram para o benefício mútuo.

4) Modelo “integrated": adota estratégias que promovam a ligação e o intercâmbio com um sistema de saúde, podendo contribuir para a criação de uma base de conhecimento fácil de usar, convocar diálogos e encontros e ofertar cursos de capacitação de rotina.

Ante ao exposto, a estratégia utilizada pela SEVS/PE se enquadra no modelo "exchange" de translação do conhecimento proposto por Bennett e Jessani, em 2011, baseado na parceria entre pesquisadores e utilizadores do conhecimento colaborando para o benefício mútuo. Nesse caso, a parceria se deu entre a gestão da vigilância em saúde, que contribuiu com a definição do foco da produção de novos conhecimentos, e os profissionais que aspiravam ao título de mestre, e ocupavam várias posições na "complexa teia organizacional" (HARTZ, 2013) - pesquisador, influenciador e utilizador do conhecimento.

\section{Considerações finais}

O duplo papel desempenhado no mestrado profissional: pesquisador e técnico/ gestor dos serviços de saúde foi determinante para a translação do conhecimento das avaliaçôes realizadas na Secretaria Executiva de Vigilância em Saúde de Pernambuco. A participação dos potenciais usuários do conhecimento na sua (re) construção, desde o momento da definição do problema, até o seu uso e aplicação se deveu em grande medida à prévia influência dos pesquisadores no grupo de 
interessados, o que legitimou o processo (ABREU et al., 2017; BEZERRA; CAZARIN; ALVES, 2010; FIGUEIRÓ et al., 2012; GAGLIARD et al., 2016; HARTZ, 2013; VINGILIS et al., 2003). Estar inserido no contexto foi vital para a análise do público e do momento ideal para difusão e disseminação do conhecimento produzido (GRAHAM, 2006). As mudanças ocorridas em decorrência dos resultados das pesquisas foram desde a criação de novas agendas, elaboração de protocolos e revisão de documentos, mudança do processo de trabalho, instituição de novos fluxos, até a contratação de novos profissionais.

$\mathrm{Na}$ análise geral das fases ideais da translação do conhecimento das pesquisas realizadas, a influência se deu em todas as dimensóes e níveis e os três tipos de uso foram categorizados nas evidências. A maior ocorrência foi da influência nos níveis individual e interpessoal, revelada nos resultados das pesquisas, no fim do ciclo das avaliaçóes. Ressalta-se a maior ocorrência de eventos e inscriçóes nas categorias de uso instrumental da avaliação e da influência no tempo imediato e fonte processual, indicando correspondência entre a abordagem com foco na utilidade e o favorecimento da utilização dos estudos durante o decorrer do processo de trabalho. Chamam a atenção, ainda, os eventos de natureza coletiva, indicando o interesse institucional em adotar produtos e recomendaçóes gerados pelas avaliaçóes (FIGUEIRÓ et al., 2012).

Embora o ciclo de feedback entre as fases de ação não tenha sido analisado, ou seja, como cada fase de ação pode ser influenciada pelas fases que a precederam, percebeu-se o movimento feito pela maioria dos pesquisadores para o uso e aplicação do conhecimento, superando as barreiras presentes desde a introdução do conhecimento na rotina das equipes. Porém, é importante ressaltar a importância do processo de planejamento e gerenciamento da mudança, avaliando as barreiras à sustentabilidade do conhecimento, adaptando as intervençóes a essas barreiras, monitorando o uso contínuo e avaliando o impacto do uso inicial e o uso sustentado do conhecimento, o que não foi realizado (GRAHAM et al., 2006).

A preocupação contínua com o uso e aplicação do conhecimento produzido pelas pesquisas, aliada à definiçáo de um referencial teórico para avaliar o "impacto" da pesquisa em políticas e populaçôes, com métodos claros para entender como a política funciona e como ela muda em resposta à informaçáo, possibilitará a mensuração dos efeitos da translação do conhecimento nas políticas de saúde (OLIVER; LORENC; INNVAER, 2014). 
É importante frisar a publicação de dois artigos científicos e a produção de dois capítulos de livro como forma do conhecimento circulante, para alcançar outras audiências e contribuir para melhorar ainda mais as práticas. É importante que os próximos profissionais do serviço interessados em cursos de pós-graduação incluam a TC como parte do planejamento do estudo, ainda na fase de elaboração do projeto de pesquisa, a fim de aumentar a amplitude do seu alcance e favorecer a sua sustentabilidade. ${ }^{1}$

\section{Referências}

ABREU, D. M. F. et al. Usos e influências de uma avaliação: translação de conhecimento? Saúde Debate, v. 41, especial, p. 302-316, mar. 2017.

BARBOSA, L.; PEREIRA NETO, A. Ludwik Fleck (1896-1961) e a translação do conhecimento: consideraçôes sobre a genealogia de um conceito. Saúde Debate, v. 41, especial, p. 317-329, mar. 2017.

BENNET, S. et al. Perceptions of evidence-based practice: A survey of Australian occupational therapists. Australian Occupational Therapy Journal, v. 50, p. 13-22, 2003.

BENNET, G.; JESSANI, N. The knowledge translation toolkit: bridging the know-do gap: a resource for researchers. 2011. Retrieved from: <http://web.idrc.ca/openebooks/508-3/>.

BEZERRA, L. C. A.; CAZARIN, G.; ALVES, C. K. A. Modelagem de Programas: da Teoria à Operacionalização. In: SAMICO, I. et al. Avaliação em saúde: bases conceituais e operacionais. Rio de Janeiro: MedBook, 2010, p. 65-78.

BLAKE, S. C.; OTTOSON, J. M. Knowledge utilization: Implications for evaluation. New Directions for Evaluation, v. 124, p. 21-34, 2009.

BRETT, J. L. L. Use of nursing practice research findings. Nursing Research, v. 36, p. 344-349, 1987. CANADIAN INSTITUTES OF HEALTH RESEARCH (CIHR). About knowledge translation. 2005. Retrieved September 9, 2006. Disponível em: <http://www.cihr-irsc. gc.ca/e/29418.html>.

. Guide to Knowledge Translation Planning at CIHR: Integrated and End-of-Grant Approaches. Canada: Canadian Institutes of Health Research, 2012.

CHAMPAGNE F. et al. A avaliação no campo da saúde: conceitos e métodos. In: BROUSSELLE, A. et al. Avaliação conceitos e métodos. Rio de Janeiro: Ed. Fiocruz, 2011, p. 41-60.

CRAVEIRO, I.; HARTZ, Z. Avaliação do papel das redes de investigaçấo na translação do conhecimento. In: Anais do Instituto de Higiene e Medicina Tropical. Avaliaçâo em Saúde, Ciência Aberta e Gestáo do Conhecimento, v. 15 (Supl. 2), 2016, S35-S40. 
DAVIES, B.; EDWARDS, N. Sustaining knowledge use. In: STRAUS, S.; TETROE, J.; GRAHAM, I. D. (Edit.). Knowledge Translation in Health Care: Moving from Evidence to Practice. 2. ed. Wiley Blackweel/BJM Books, 2013, p. 237-248.

DAVIS, D. Quality, Patient Safety and the Implementation of Best Evidence: Provinces in the Country of Knowledge Translation. Health Care Quarterly, v. 8, special issue, p. 128-131, oct. 2005.

DAVISON, C. M. Knowledge translation: Implications for evaluation. In: OTTOSON, J. M.; HAWE, P. (Eds.). Knowledge utilization, diffusion, implementation, transfer, and translation: Implications for evaluation. San Francisco: Wiley Subscription Services at Jossey-Bass, 2009, p. 75-87. (Serie New Directions for Evaluation, v. 124).

ESTABROOKS, C. A. The conceptual structure of research utilization. Research in Nursing \& Health, v. 22, p. 203-216, 1999.

FIGUEIRÓ, A. C. et al. Usos e influência da avaliação em saúde em dois estudos sobre o Programa Nacional de Controle da Dengue. Cad. Saúde Pública, v. 28, n. 11, p. 2095-2105, nov. 2012.

- A avaliação da rede PDTSP-Teias: contribuição ao debate sobre construção do conhecimento e de produtos para o SUS. In: SANTOS, I. S.; GOLDELSTEIN, R. A. Rede de pesquisa em Manguinhos: sociedade, gestores e pesquisadores em conexão com o SUS. São Paulo: Hucitec, 2016, p. 293-322.

GAGLIARD, A. R. et al. Integrated knowledge translation (IKT) in health care: a scoping review. Implementation Science, v. 11, n. 38, p. 1-12, 2016.

GRAHAM, I. D. et al. Lost in Knowledge Translation: Time for a Map? The Journal of Continuing Education in the Health Professions, v. 26, p. 13-24, 2006.

GRAHAM, I. D.; LOGAN, J. Inovations in knowledge transfer and continuity of care. Canadian Journal of Nursing Research, v. 36, n. 2, p. 89-103, 2004.

GRAVEL, K.; LÉGARÉ, F.; GRAHAM, I. D. Barriers and facilitators to implementing shared decision-making in clinical practice: a systematic review of health professionals' perceptions. Implementation Science, v. 1, n. 16, p. 1-15, 2006.

HARTZ, Z. M. A. (Org.) Avaliação em Saúde: dos modelos conceituais à prática na análise da implantação de programas. Rio de Janeiro: Ed. Fiocruz, 1997, p. 132. ISBN 85-85676-36-1. Disponível em: <http:// books.scielo.org>.

. Contextualizando a implantação das intervençôes e da avaliação em saúde: um ensaio pragmático. In: SAMICO, I. et al. Formação Profissional e Avaliação em Saúde - Desafios na Implantação de Programas. Rio de Janeiro: MedBook, 2013. 244 p. 
HARTZ, Z. M. A. et al. From knowledge to action: challenges and opportunities for increasing the use of evaluation in health promotion policies and practices. In: MCQUEEN, D. V.; POTVIN, L. (Edit.). Health promotion evaluation practices in the Americas: values and research. New York: Springer, 2008, p. 101-20.

HENRY, G. T.; MARK, M. M. Beyond Use: understanding envaluation's influence on attitudes and actions. American Journal Evaluation, v. 24, n. 3, p. 293-314, 2003.

JACOBSON, N.; BUTTERILL, D.; GOERING, P. Development of a framework for knowledge translation: understanding user context. Journal of Health Services Research \& Policy, v. 8, n. 2, p. 94-99, 2003.

JOHNSON, L. S. From knowledge transfer to knowledge translation: Applying research to practice. OT Now, Ottawa, p. 11-14, July/August 2005.

LAVIS, J. et al. Assessing country-levels Efforts to Link Research to Action. Bulletin of the World health Organization, v. 84, p. 620-628, 2006.

MELINE, T.; PARADISO, T. Evidence-Based Practice in Schools: Evaluating Research and Reducing Barriers. Language, Speech, and Hearing Services in Schools, v. 34, p. 273-283, Oct. 2003.

MICHEL, Y.; SNEED, N. V. Dissemination and use of research findings in nursing practice. Journal of Professional Nursing, v. 11, p. 306-311, 1995.

OELKE, N. D.; LIMA, M. A. D. S.; ACOSTA, A. M. Translação do conhecimento: traduzindo pesquisa para o uso na prática e na formulação de políticas. Revista Gaúcha Enfermagem, Porto Alegre, v. 36, n. 3, p. 113-117, set. 2015.

OLIVER, K.; LORENC, T.; INNVAER, S. New directions in evidence-based policy research: a critical analysis of the literature. Health Research Policy and Systems, v. 12, n. 34, p. 1-11, 2014.

O'TOOLE, L. J. Research on policy implementation: Assessment and prospects. Journal of Public Administration Research and Theory, v. 10, n. 2, p. 263-288, 2000.

OTTOSON, J. M. Knowledge-for-action theories in evaluation: Knowledge utilization, diffusion, implementation, transfer, and translation. In: OTTOSON, J. M.; HAWE, P. (Eds.). Knowledge utilization, diffusion, implementation, transfer, and translation: Implications for evaluation. San Francisco: Wiley Subscription Services at Jossey-Bass, 2009, p. 7-20. (Serie New Directions for Evaluation, v. 124).

PUBLIC HEALTH AGENCY OF CANADA (PHAC). Knowledge translation planning primer. To promote and protect the health of canadians through leadership, partnership, innovation and action in public health. Canada, 2012.

ROGERS, E. Diffusion of innovations. 5. ed. New York: Free Press, 2003. 
SUDSAWAD, P. Knowledge translation: Introduction to models, strategies, and measures. Austin, TX: Southwest Educational Development Laboratory, National Center for the Dissemination of Disability Research, 2007. Disponível em: <http://www.ncddr.org/kt/products/ktintro/>.

TRICCO, A. C. et al. Barriers and facilitators to uptake of systematic reviews by policymakers and health care managers: a scoping review. Implementation Science, v. 11, n. 4, p. 1-20, 2016.

VINGILIS, E. et al. Integrating Knowledge Generation with Knowledge Diffusion and Utilization: A Case Study Analysis of the Consortium for Applied Research and Evaluation in Mental Health. Revue Canadienne de Santé Publique, v. 94, n. 6, p. 468-471. Nov.-dez. 2003.

WEISS, C. H.; MURPHY-GRAHAM, E.; BIRKELAND, S. An alternative route to policy influence: how evaluations affect D.A.R.E. American Journal of Evaluation, v. 26, n. 1, p. 1230, Mar. 2005.

WORLD HEALTH ORGANIZATION (WHO). Bridging the "Know-Do" GapMeeting on Knowledge Translation in Global Health. Geneva, Switzerland: World Health Organization, 2005. . Bridging the "know-do" gap: Meeting on knowledge translation in global health. Geneva: World Health Organization, 2006.

\section{Nota}

${ }^{1}$ L. Bezerra foi responsável pela concepção, interpretação dos dados, análise e redação do artigo. E. Felisberto participou da concepção, redação do artigo e revisão crítica do conteúdo. J. Costa realizou a interpretação dos dados, análise e redação do artigo. Z. Hartz participou da concepção, redação do artigo, revisão crítica do conteúdo e aprovaçáo final da versão a ser publicada do artigo. 


\section{Abstract}

Knowledge Translation in qualification of Health Surveillance management: contribution of postgraduate evaluative studies There are many challenges in minimizing the gaps between scientific evidence and better health outcomes. The translation of knowledge (TC) is the movement that knowledge makes in an organizational context in favor of its effective application. This study aimed to analyze the occurrence of $\mathrm{CT}$ in the Executive Secretariat of Health Surveillance of Pernambuco (SEVS / PE), focusing on 10 evaluative surveys on Health Surveillance programs, produced in the Master's Degree in Health Evaluation of the Institute of Comprehensive Medicine Prof. Fernando Figueira, from 2011 to 2015. For this purpose, a semi-structured interview script was used, addressing 7 managers and 10 SEVS-PE technicians. In the analysis of this qualitative case study, a CT model was used, and overlapping it, a theoretical structure of use-influence of the evaluation. In eight studies analyzed, evidence was categorized into five phases of CT. Only the evaluation stage of the use of knowledge was not evidenced. Different types of use, dimensions and influence levels of the evaluations were reported. Among the changes occurred, the following were reported: creation of new agendas, elaboration of protocols, change of work process, creation of new flows, hiring of new professionals.

> Keywords: knowledge translation; knowledge management; health policies; health management; health surveillance. 